\title{
Tolerability of Topical Treatments for Atopic Dermatitis
}

Zoe D. Draelos · Steven R. Feldman · Brian Berman • Melissa Olivadoti •

Debra Sierka · Anna M. Tallman • Michael A. Zielinski •

William C. Ports · Sheryl Baldwin

Received: October 24, 2018 / Published online: January 24, 2019

(C) The Author(s) 2019

\section{ABSTRACT}

Atopic dermatitis (AD) is a common inflammatory skin disease that is accompanied by increased sensitivity to itch-provoking and pain-provoking stimuli. Patients with AD experience skin pain before initiation of therapy and have also reported painful application site reactions in clinical trials of emollients and prescription topical therapies, including topical corticosteroids (TCSs), topical calcineurin

Enhanced digital features To view enhanced digital features for this article go to https://doi.org/10.6084/ m9.figshare.7547330.

Z. D. Draelos ( $₫)$

Dermatology Consulting Services, High Point, NC, USA

e-mail: zdraelos@northstate.net

S. R. Feldman

Wake Forest School of Medicine, Winston-Salem, NC, USA

B. Berman

Skin and Cancer Associates, Aventura, FL, USA

M. Olivadoti · M. A. Zielinski

Pfizer Inc., Collegeville, PA, USA

D. Sierka · A. M. Tallman

Pfizer Inc., New York, NY, USA

W. C. Ports

Pfizer Inc., Groton, CT, USA

S. Baldwin

Pfizer Inc., San Francisco, CA, USA inhibitors (TCIs), and a topical phosphodiesterase 4 (PDE4) inhibitor. To compare the sensory tolerability of prescription topical therapies for $\mathrm{AD}$, a comprehensive literature search and analysis of published clinical trials was conducted. Sensory tolerability issues such as application site pain, burning, stinging, and pruritus were often among the most common adverse events or treatment-related adverse events in clinical trials for prescription topical therapies. Tolerability issues occurred at highest rates in trials of TCIs, followed by trials of the PDE4 inhibitor crisaborole and TCSs, although direct comparisons are not possible because of differences in study design. Tolerability issues in these clinical trials were generally mild to moderate and transient. This article also reviews published strategies for managing sensory tolerability issues in $\mathrm{AD}$ patients during treatment with topical therapies.

Funding: Pfizer Inc., New York, NY.

Keywords: Atopic dermatitis; Application site pain; Application site reaction; Calcineurin inhibitor; Corticosteroid; Crisaborole; Tolerability; Topical therapy

\section{INTRODUCTION}

Atopic dermatitis (AD) is a chronic inflammatory skin disease characterized by eczematous 
lesions and pruritus that affects up to $15-30 \%$ of children and $2-10 \%$ of adults $[1,2]$. In one study, the prevalence of baseline skin pain in $\mathrm{AD}$ was $42.7 \%$, with $13.8 \%$ of patients experiencing severe or very severe pain [3], although some studies estimate pain prevalence rates exceeding 50\% [4] and 80\% [5]. High prevalence of pain may relate to skin sensitivity. Patients with $\mathrm{AD}$ are more likely than healthy individuals to report hypersensitivity to lactic acid [6], nonhistaminergic chemical stimuli [7], and pain- and itch-provoking mechanical stimuli [7]. Proposed mechanisms of skin sensitivity and pain in $\mathrm{AD}$ include epidermal barrier disruption, leading to increased exposure of cutaneous nerve endings and heightened vulnerability to environmental irritants; increased density or length of cutaneous nerve fibers; and inflammation-mediated sensitization of afferent neurons containing receptors for pain, itch, and warmth such as transient receptor potential cation channel subfamily $\mathrm{V}$ member 1 (TRPV1) [3, 7-9]. Scratching is also a likely source of pain because pain prevalence is significantly associated with having skin excoriations [3].

Topical therapies are the cornerstone of $\mathrm{AD}$ management, beginning with emollients and moisturizers as first-line therapies [10-12]. Topical corticosteroids (TCSs), which suppress antigen processing and proinflammatory cytokine release in immune cells, are first-line antiinflammatory therapies [10-12]. Second-line therapies include topical calcineurin inhibitors (TCIs), which inhibit calcineurin-dependent activation of T cells [10]. TCIs are recommended for $\mathrm{AD}$ unresponsive to TCSs, for situations in which TCS use is inadvisable, and for proactive maintenance (application 2-3 times weekly to flare-prone areas) [10-12]. Crisaborole is a nonsteroidal phosphodiesterase 4 inhibitor for the treatment of mild to moderate AD [13]. Crisaborole is recommended by the American College of Allergy, Asthma, and Immunology AD Yardstick, a tool that is intended to supplement published guidelines with the most recent clinical and research findings, for second-line therapy, for patients intolerant of TCSs or TCIs, and for maintenance [14].
Application of topical treatments can exacerbate baseline pain and produce other skin sensory adverse events (AEs) in AD. Tolerability events including skin burning, stinging, and pruritus have been reported with certain emollient formulations [15-18]. TCIs are commonly associated with application site (AS) burning and stinging [10-12], and AS burning and pruritus have been reported for TCSs $[19,20]$. AS pain has been reported in clinical trials of crisaborole $[21,22]$. The objective of this review is to synthesize published data on the sensory tolerability of topical prescription products for $\mathrm{AD}$ and to provide clinical recommendations on mitigation strategies for tolerability issues. We define sensory tolerability issues as burning, stinging, pain, irritation, pruritus, or paresthesia.

\section{LITERATURE ANALYSIS}

To compare the sensory tolerability of currently available, prescription topical treatments for $\mathrm{AD}$, we performed a literature analysis (see Fig. 1). Treatment-emergent AEs (TEAEs), treatment-related AEs (TRAEs), and discontinuations relevant to tolerability are summarized in Tables 1, 2, 3 and 4. AS-specific data were included whenever available.

This article is based on previously conducted studies and does not contain any studies with human participants or animals performed by any of the authors.

\section{TOLERABILITY OF TCls}

Most studies meeting inclusion criteria evaluated TCIs (Table 1). Among 19 studies assessing pimecrolimus cream, 1\% (not compared with tacrolimus), six evaluated short-term treatment (6-12 weeks) [23-28]. All six studies were vehicle controlled for at least part of the study and, with the exception of one study [23] evaluating pimecrolimus combination therapy with TCSs in severe $\mathrm{AD}$, they enrolled patients with mild to moderate $\mathrm{AD}$ and did not allow TCSs as concomitant therapy. Prevalence rates of burning/pain/irritation ranged from $1.6 \%$ to 


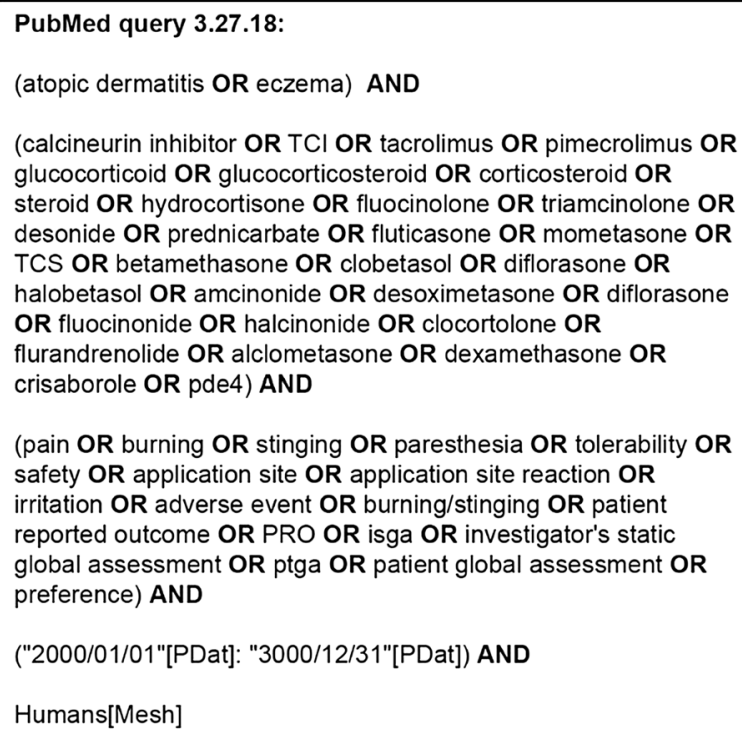

Fig. 1 PubMed search terms and filters applied in literature analysis. $A D$ atopic dermatitis, $P D E 4$ phosphodiesterase type 4, PRO patient-reported outcome, ISGA

$26.7 \%$ (pimecrolimus) and $1.0 \%$ to $22.2 \%$ (vehicle). Five of the short-term studies cited burning and/or irritation among the most common TEAEs [24-27] or cutaneous AEs [28]. Thirteen pimecrolimus studies evaluated longterm (approximately 5 months to 1 year) therapy, of which six were controlled, double-blind studies [29-34], four were open-label [35-38], and three had both double-blind and open-label phases [39-41]. Eleven long-term studies allowed occasional treatment with TCSs as rescue therapy for flares [29-38, 40]. Among longterm studies providing overall event-specific rates, rates of AS burning ranged from $0.8 \%$ to $10.5 \%$ (pimecrolimus) and $1.1 \%$ to $9.3 \%$ (vehicle/conventional therapy). Seven studies cited tolerability-related AS issues (burning, stinging, pruritus, pain) among the most common AEs [31-33, 35-38]. Eleven pimecrolimus studies (two short-term and nine long-term) provided information on the severity and timing of AS tolerability issues, describing them as predominantly mild to moderate, transient, and/or occurring early in treatment [24, 28, 31-39].

Fifteen studies evaluated tacrolimus ointment, $0.03 \%$ or $0.1 \%$ (not compared with pimecrolimus). Five studies assessed short-term

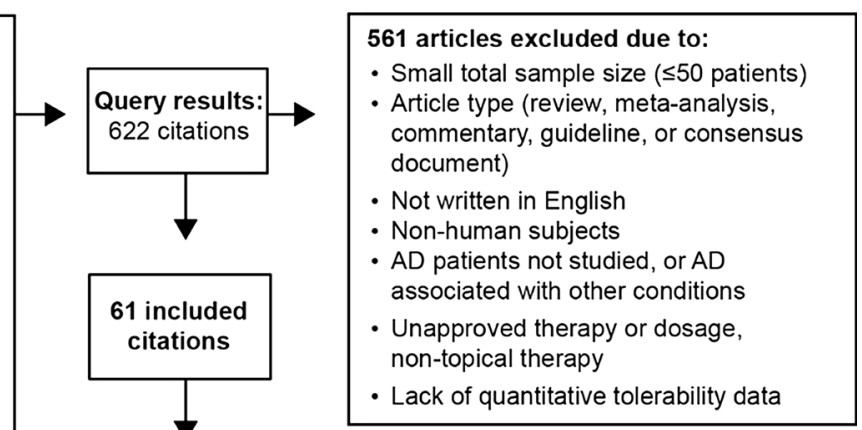

Investigator's Static Global Assessment, TCIs topical calcineurin inhibitors, TCSs topical corticosteroids

treatment (4-12 weeks), two of which were vehicle controlled [42-46]. Among three shortterm studies providing overall rates or for which overall rates could be calculated, rates of skin burning and pruritus ranged from $19.0 \%$ to $52.9 \%$ and $16.4 \%$ to $33.8 \%$, respectively, in tacrolimus-treated patients versus rates of $17.0 \%$ and $33.3 \%$ in vehicle-treated patients. Kang et al. [42] reported significantly higher rates of AS burning in groups receiving 12 weeks of treatment with tacrolimus $0.03 \%$ or $0.1 \%$ than in the vehicle group for head/neck $(p<0.01)$ and non-head/neck $(p<0.001)$ areas, and higher prevalence of AS pruritus in the tacrolimus groups than in the vehicle group for non-head/neck areas $(p<0.05)$. One other short-term study [43] included both $0.03 \%$ and $0.1 \%$ groups, reporting a numerically higher rate of AS burning in adults treated with $0.1 \%$ tacrolimus $(69.0 \%)$ than in children treated with $0.03 \%$ tacrolimus $(26.9 \%)$, potentially because of the higher strength of tacrolimus used by adults. Schachner et al. [44] reported similar rates of AS burning/stinging in vehicletreated (17.0\%) and tacrolimus-treated (19.0\%) children with mild to moderate AD. However, burning/stinging with tacrolimus application 


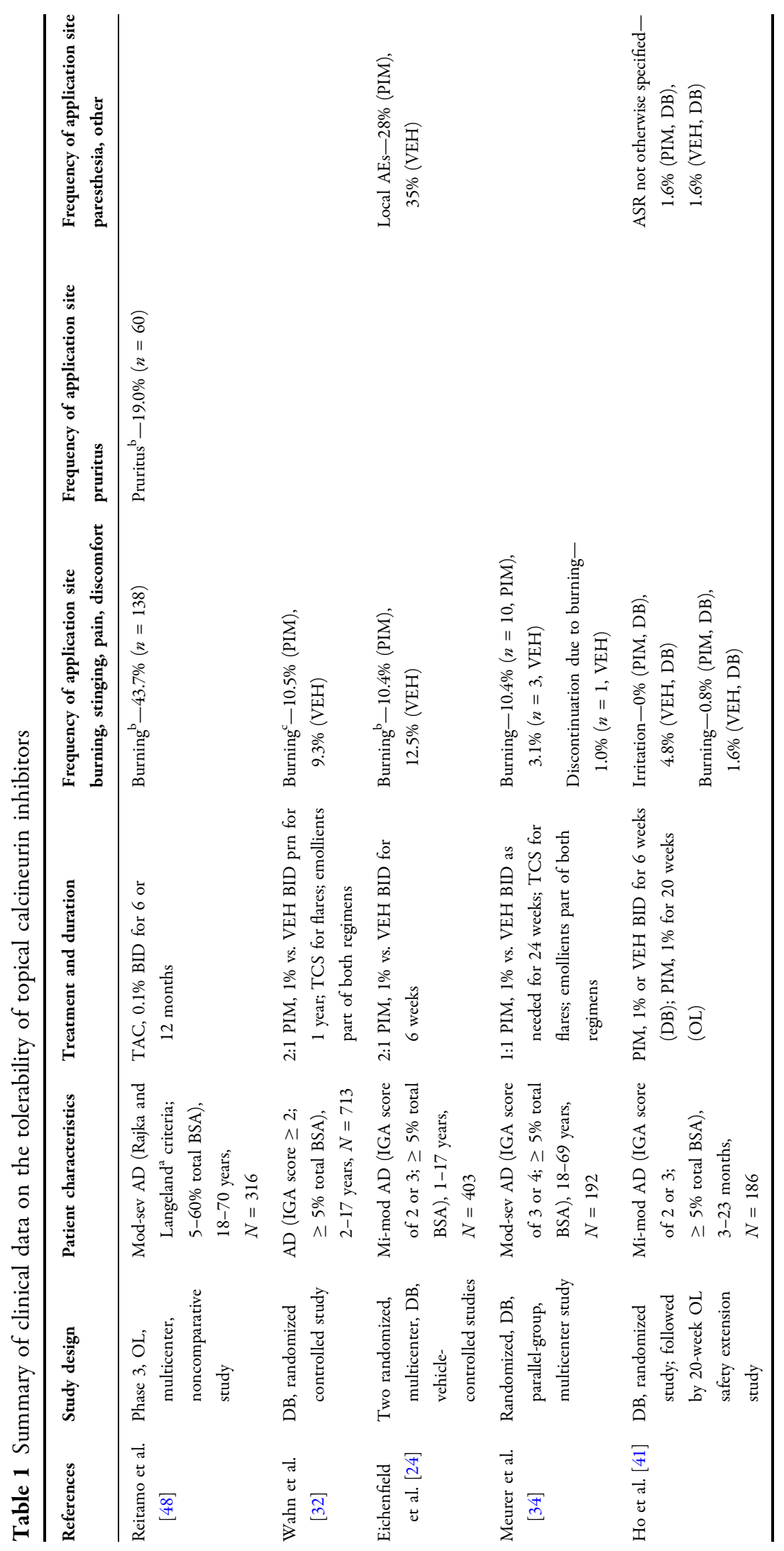




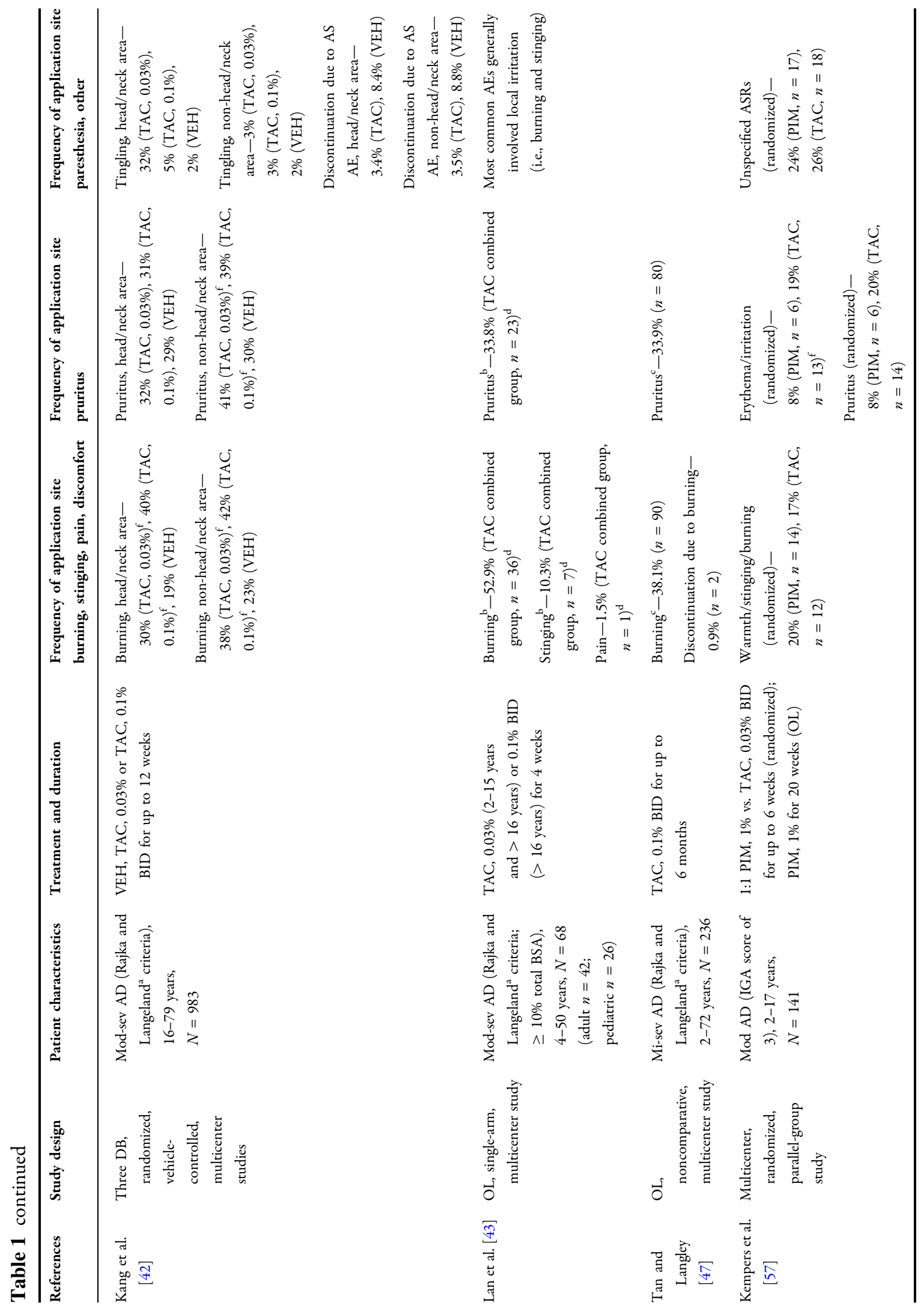




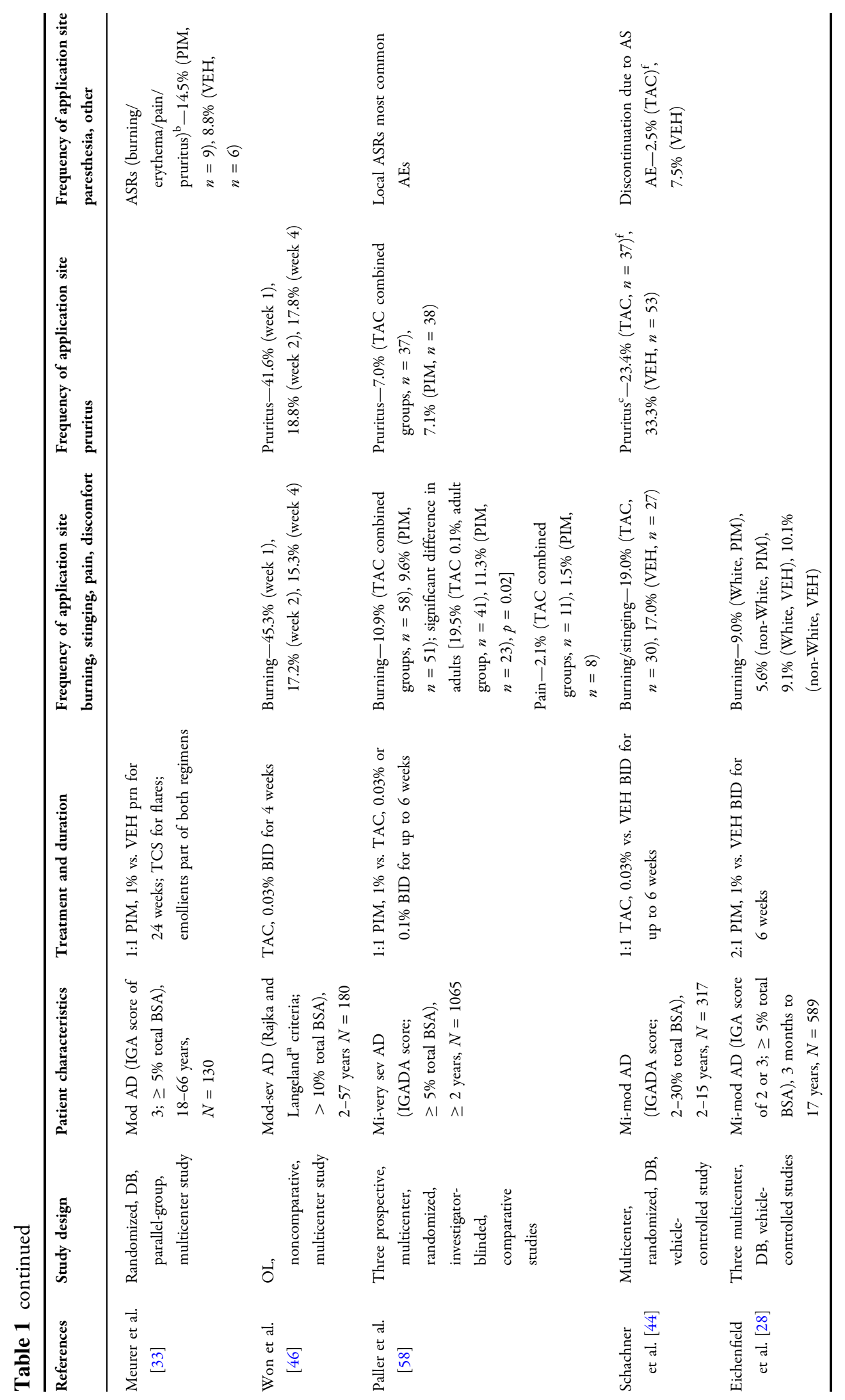




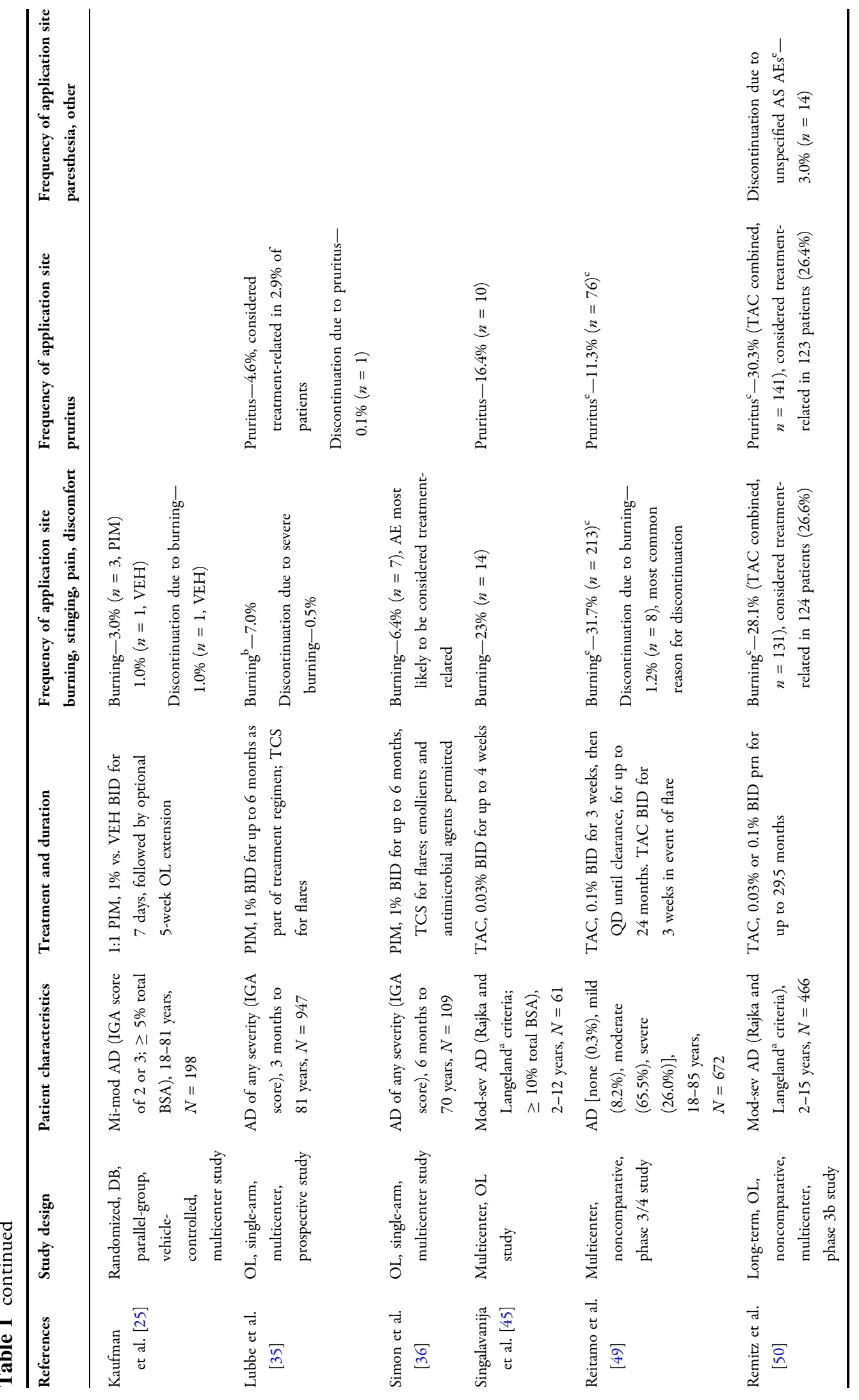




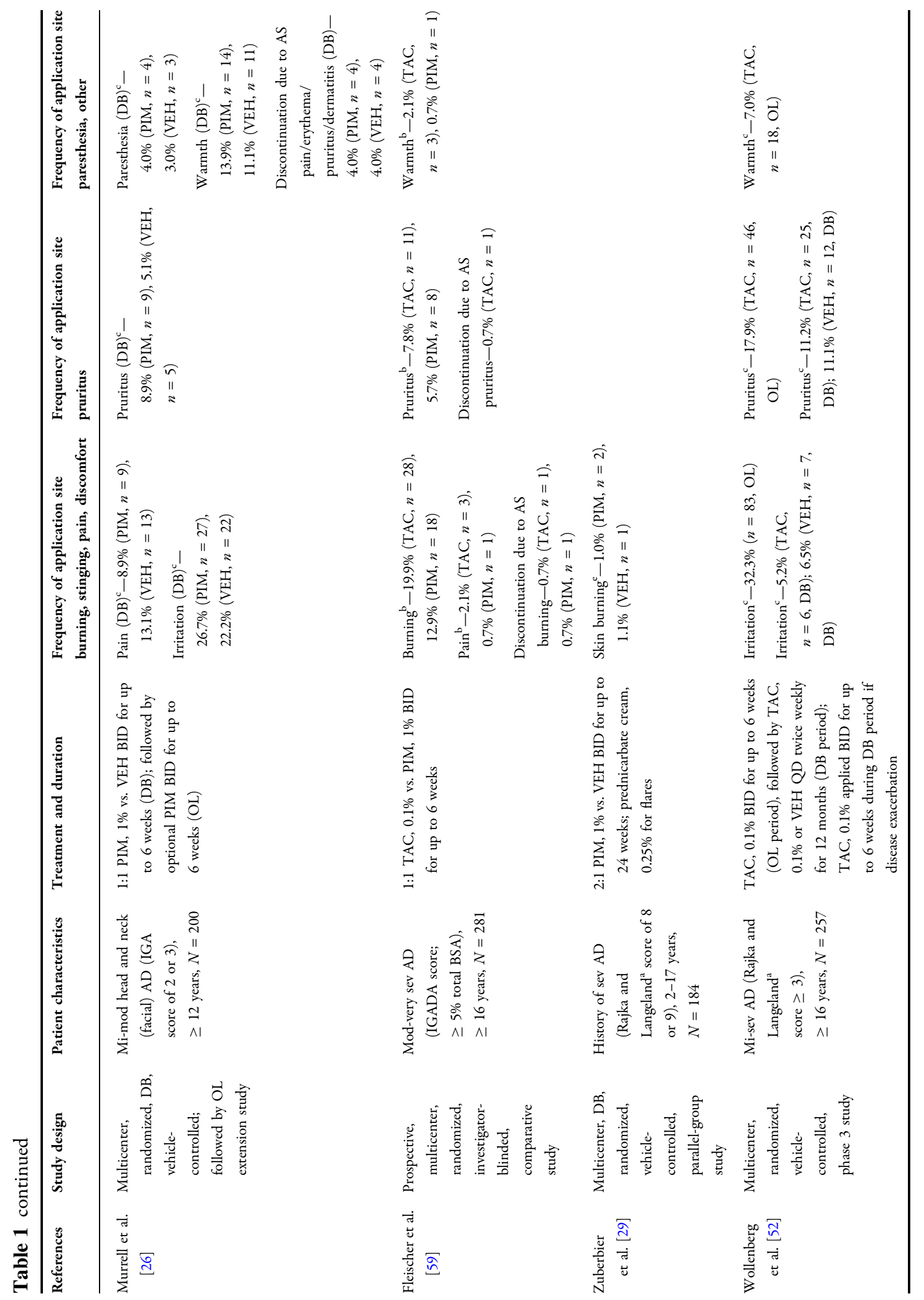




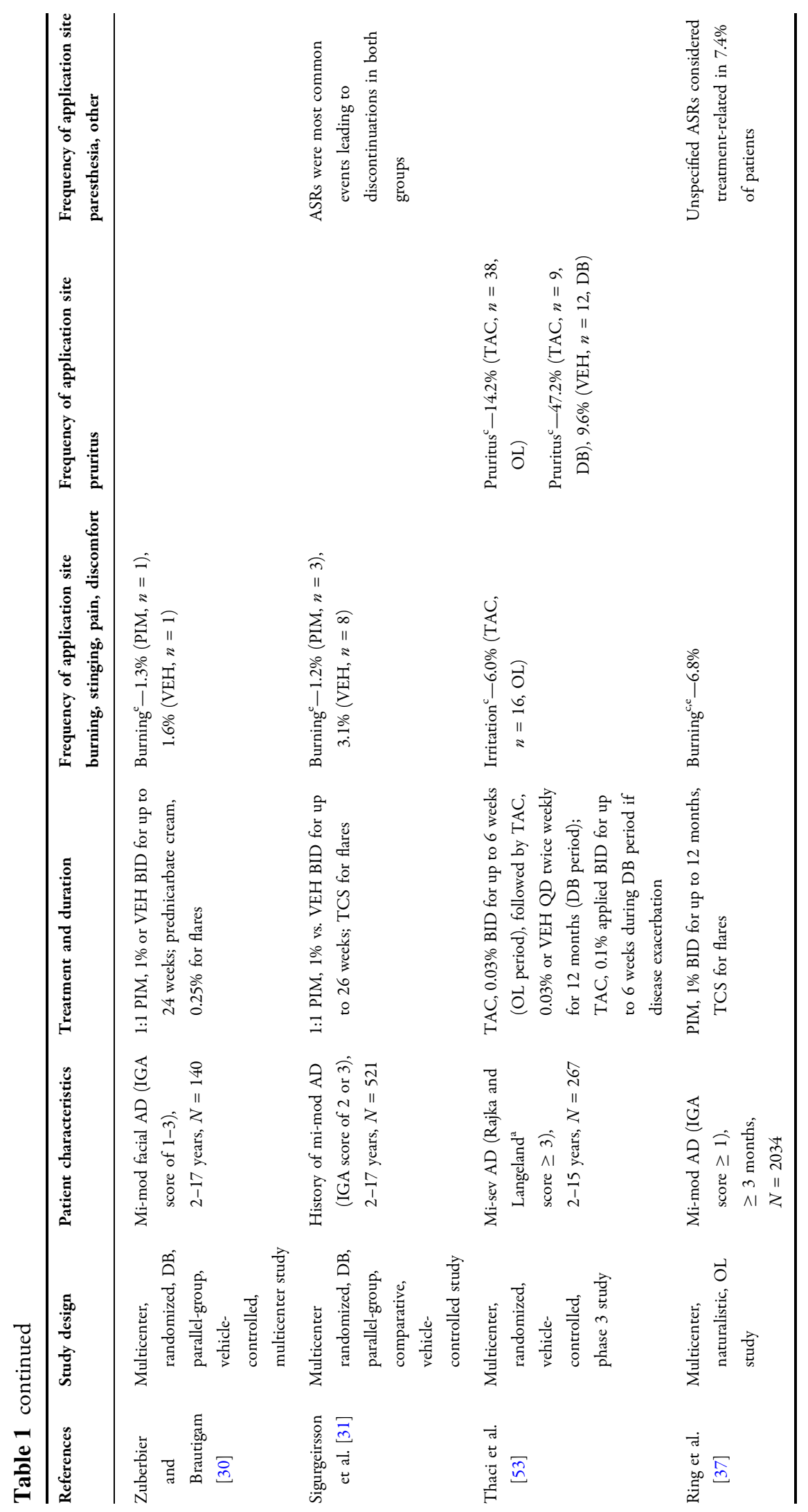




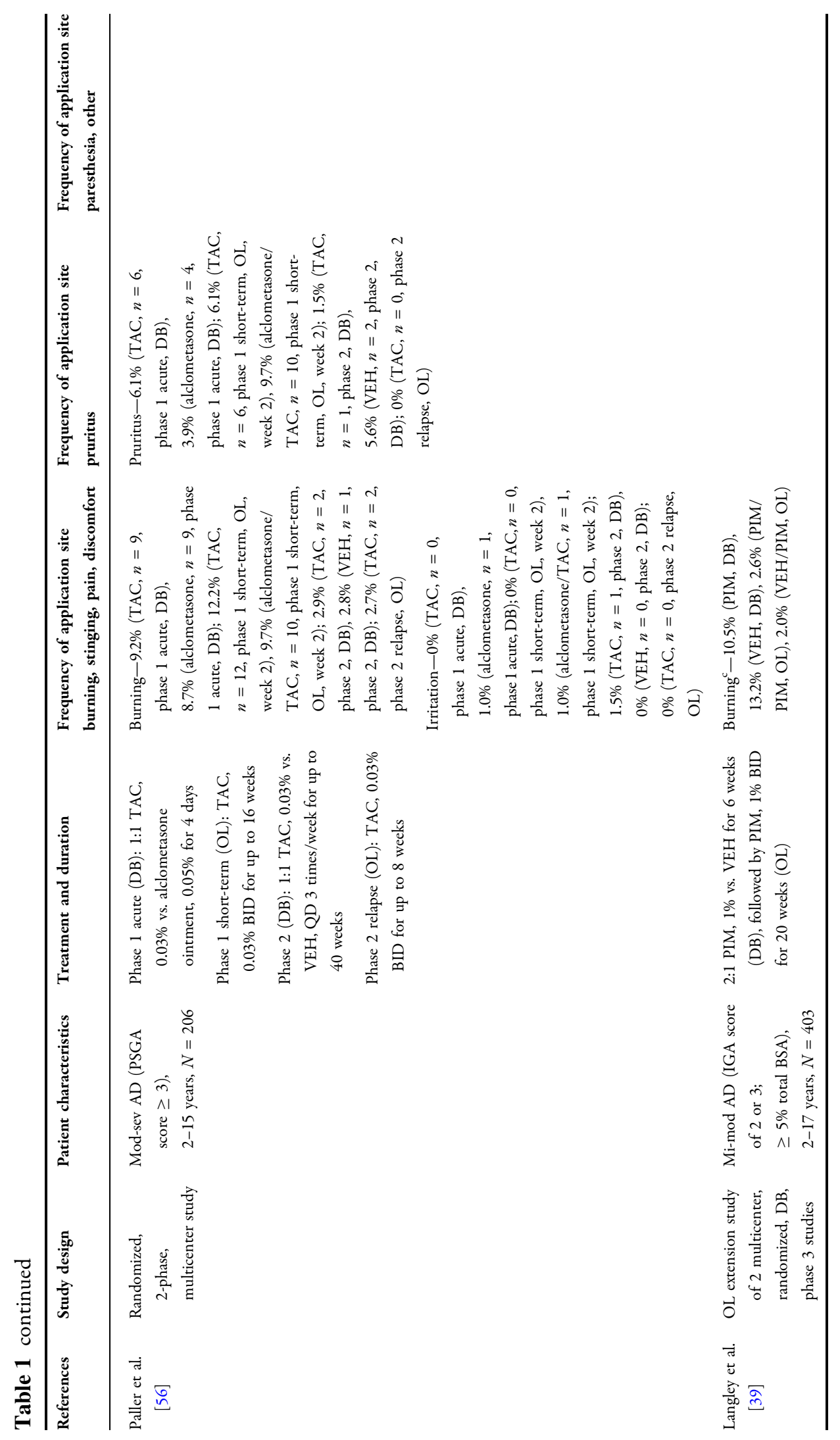




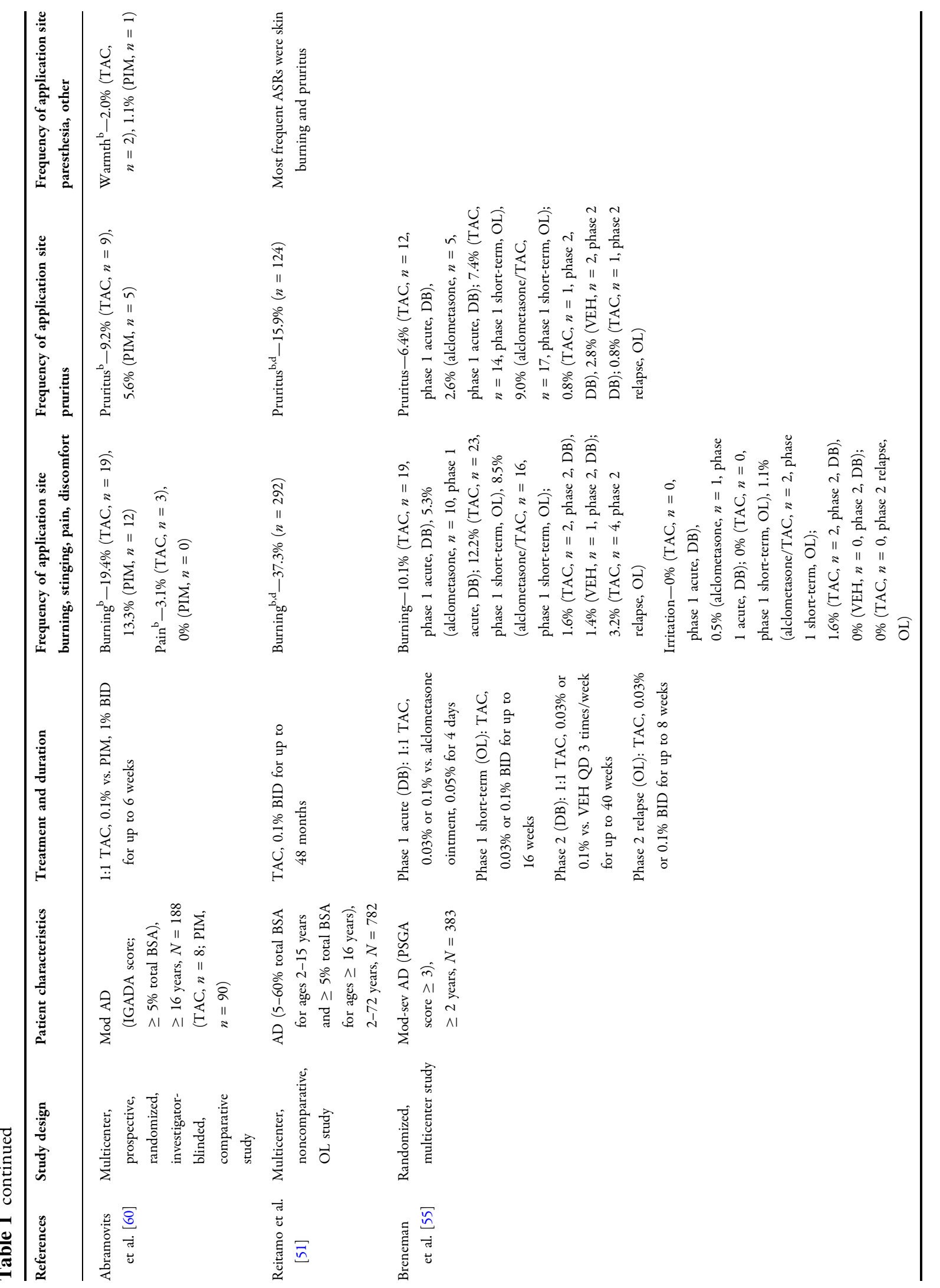




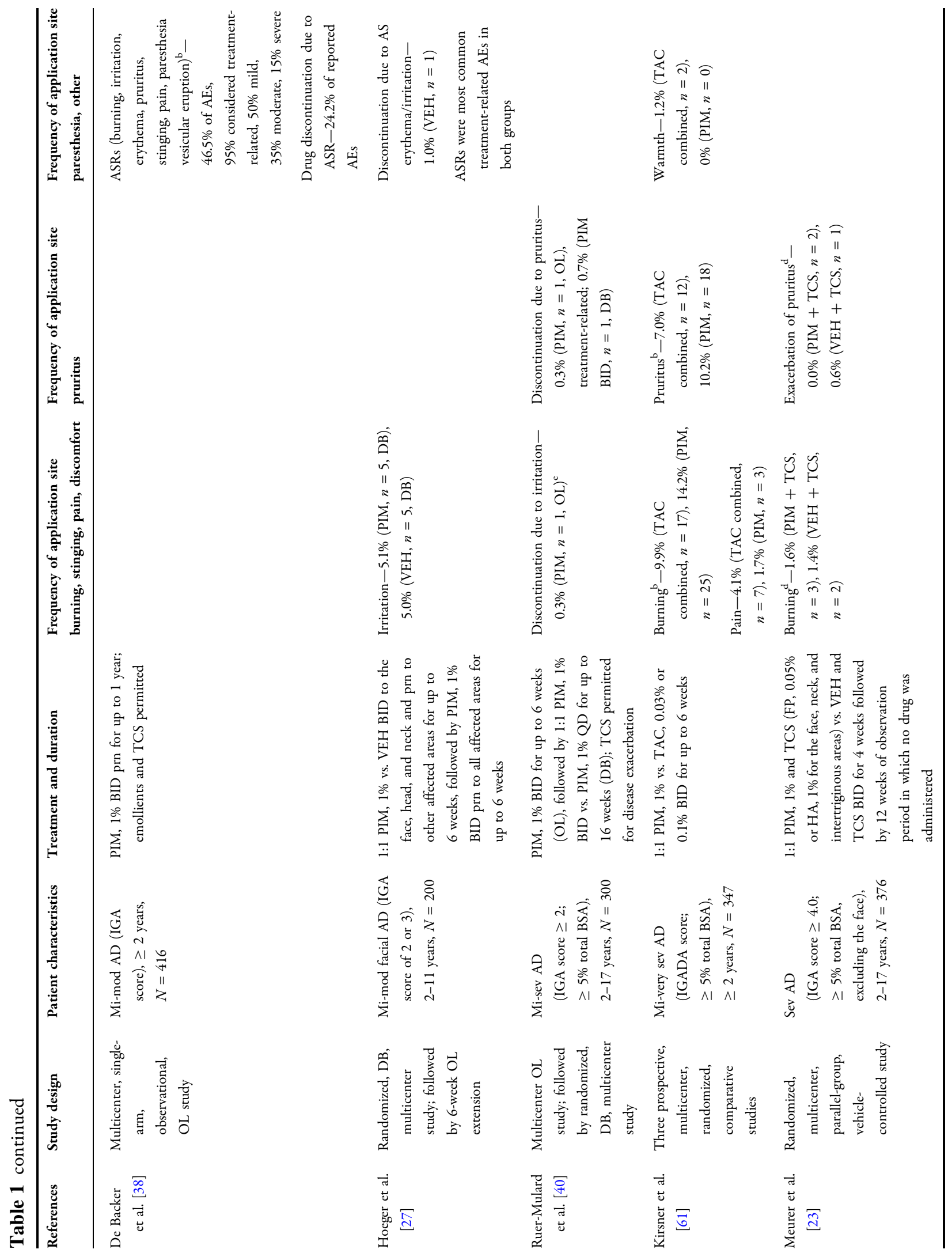




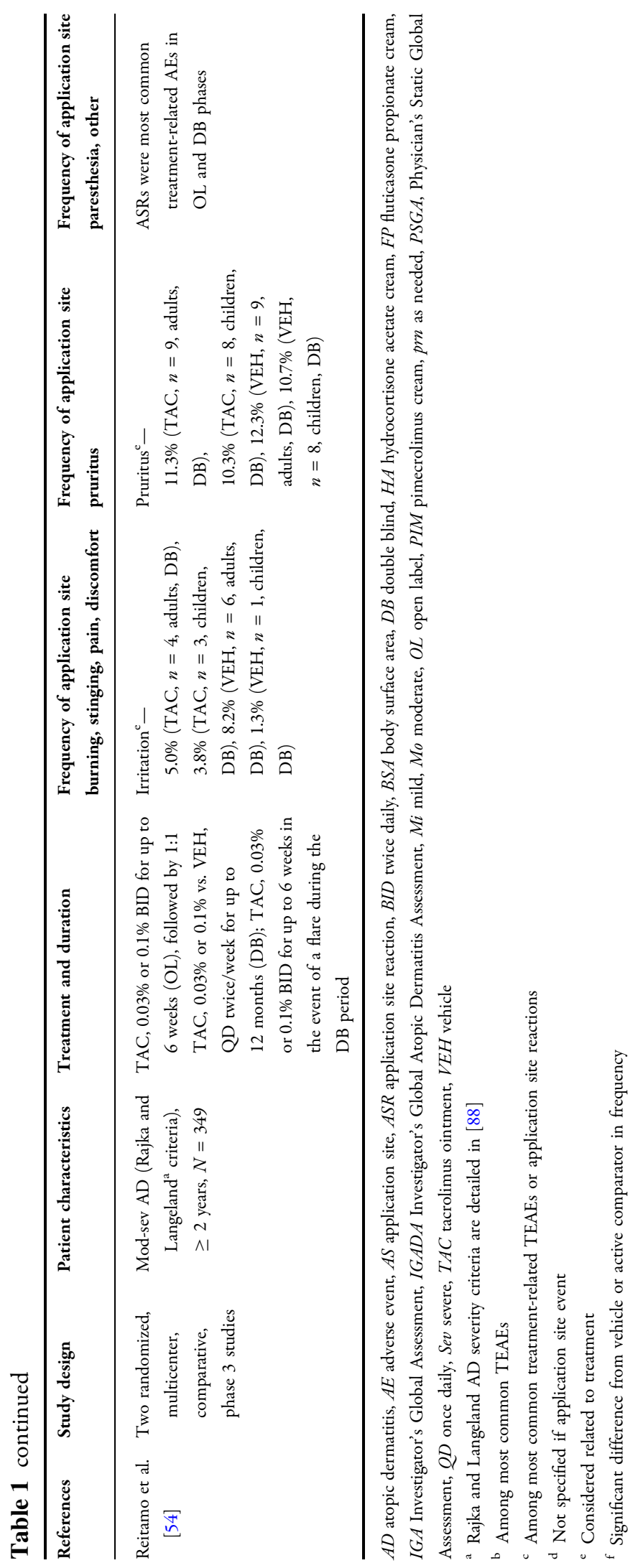


was more common in children with moderate than mild AD (29.5\% vs. $12.4 \%, p=0.008)$. Two of the five studies described severity and timing of AS tolerability issues, describing AS burning, stinging, and tingling as mild to moderate and transient [42], and AS burning and pruritus as resolving within the first week of treatment [45]. Ten tacrolimus studies involved long-term therapy (6-29.5 months), of which five were open label [47-51] and five included both double-blind and open-label phases [52-56]. Among five long-term studies providing overall rates or for which overall rates could be calculated, rates of AS burning/irritation and pruritus ranged from $4.4 \%$ to $43.7 \%$ and $10.7 \%$ to $33.9 \%$, respectively, in tacrolimus-treated patients versus $4.7 \%$ and $11.5 \%$ in vehicletreated patients. Seven long-term studies indicated that burning, irritation, and/or pruritus were among the most common AEs and/or treatment-related AEs [48-54], and five studies specified that burning and/or pruritus events were generally mild to moderate and/or decreased in prevalence over time [47-51].

Five studies directly compared tacrolimus ointment, $0.03 \%$ or $0.1 \%$ to pimecrolimus cream, $1 \%$ and all evaluated short-term treatment (up to 6 weeks) [57-61]. Four of these studies indicated that AS burning and pruritus were among the most common AEs in TCItreated patients [58-61]. Kempers et al. [57] reported a significantly greater rate $(p=0.039)$ of AS erythema/irritation in tacrolimus-treated children with moderate AD (19\%) than in pimecrolimus-treated children (8\%) and a trend toward a higher rate of AS pruritus in the tacrolimus group, but this finding was not significant ( $p=0.073$ ) [57]. Although incidence of local AEs generally decreased over time, AS erythema/irritation and warmth/burning/stinging events were more likely $(p<0.001)$ to last more than $30 \mathrm{~min}$ in tacrolimus-treated than pimecrolimus-treated children. Another study [58] reported a higher rate $(p=0.02)$ of AS burning in tacrolimus-treated adults with mild to severe $\mathrm{AD}(19.5 \%)$ than in pimecrolimustreated adults (11.3\%). Significance was driven by a greater rate of burning in tacrolimus-treated patients ( $11.4 \%$ vs. $4.9 \%)$ in the first week of treatment, after which rates were comparable.
These differences may be a result of greater skin penetration of tacrolimus compared with pimecrolimus [62].

\section{TOLERABILITY OF TCSS}

Among the 11 included trials of TCSs, overall prevalence rates of burning, pruritus, irritation, or warmth in TCS-treated patients ranged from less than $1 \%$ to $6 \%$ (Table 2). Three studies evaluated fluticasone propionate (FP), $0.05 \%$ cream [20,63] or lotion [64]. Eichenfield et al. [64] reported burning/stinging in $1.8 \%$ of children and adults with moderate to severe $\mathrm{AD}$ receiving up to 1 month of treatment with FP lotion (vehicle, $1.4 \%$ ), and pruritus in $0.5 \%$ of FP-treated patients (vehicle, $0.5 \%$ ). Both events were considered possibly related to treatment, but the authors did not specify whether the events were AS-specific. An open-label study of 3-4 weeks of treatment with FP cream in children with moderate to severe $\mathrm{AD}$ reported $\mathrm{AS}$ burning that resolved within 1 day in $2.0 \%$ of patients [20]. Another study comparing up to 4 months of treatment with FP cream to hydrocortisone cream (HC), 1\% or hydrocortisone butyrate (HCB) cream, $0.1 \%$ in children with moderate to severe $\mathrm{AD}$ reported no $\mathrm{AS}$ tolerability issues in FP- or HC-treated patients and AS pruritus in 3.2\% of HCB-treated patients [63]. Other included trials of HCB involved 4 weeks of application of HCB lipocream, 0.1\% [65] or lotion, $0.1 \%$ [66] in children and adolescents with mild to moderate $\mathrm{AD}$ and reported numerically lower rates of AS tolerability issues (1\% each for burning [66] and irritation [65], respectively).

Two studies investigated 4 weeks of treatment with desonide, $0.05 \%$ in children and adolescents with mild to moderate AD, testing either the hydrogel [19] or the foam [67] formulation. Burning was among the most common AS AEs for both formulations, occurring in $1 \%$ (hydrogel) and 3\% (foam vs. $7 \%$ in vehicle group, $p=0.004$ ) of patients. In both studies, AS pruritus occurred in less than $1 \%$ of desonidetreated patients.

Long-term treatment (4-6 months) with mometasone furoate (MF) fatty cream, 0.1\% [68] 


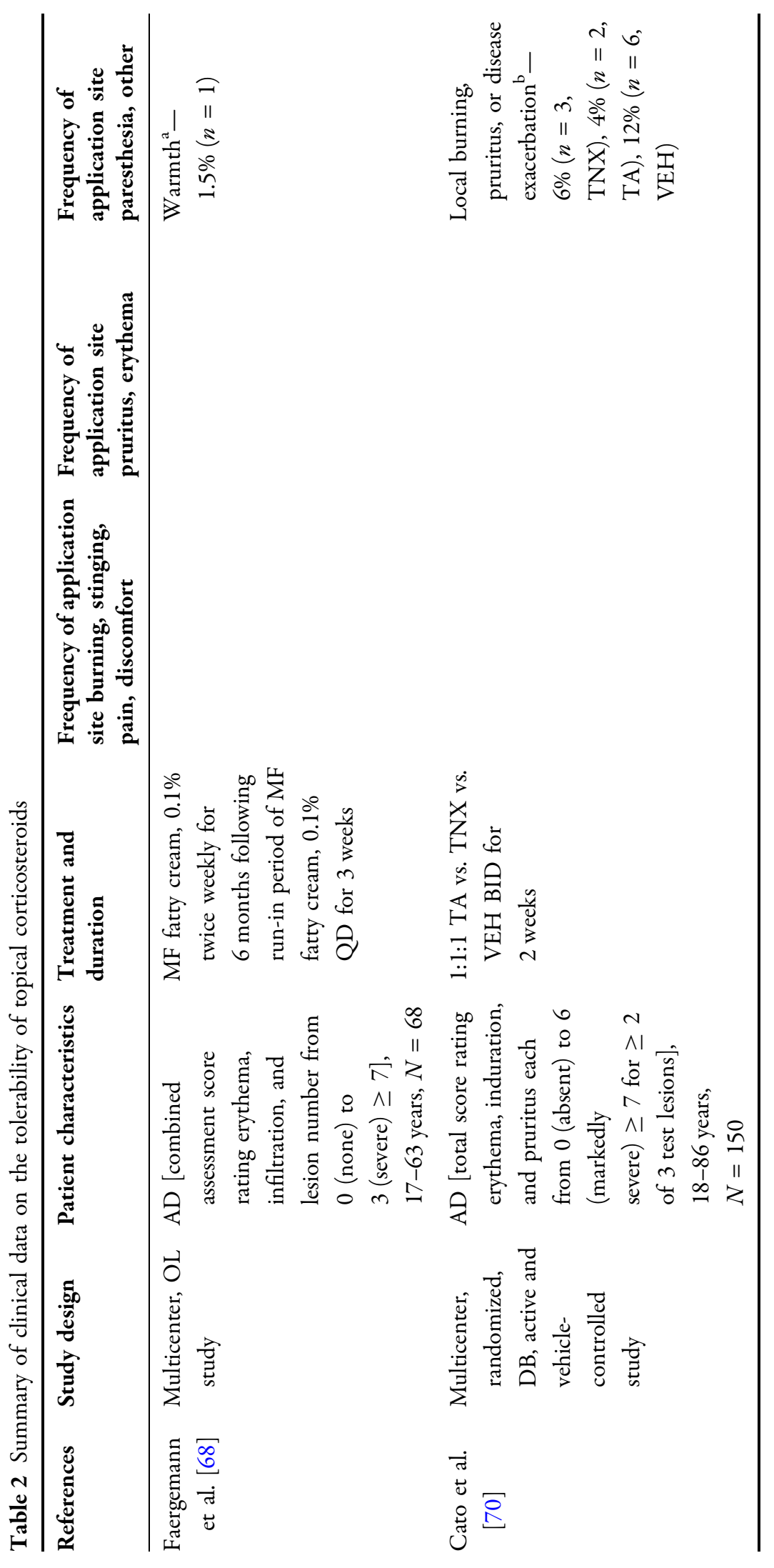




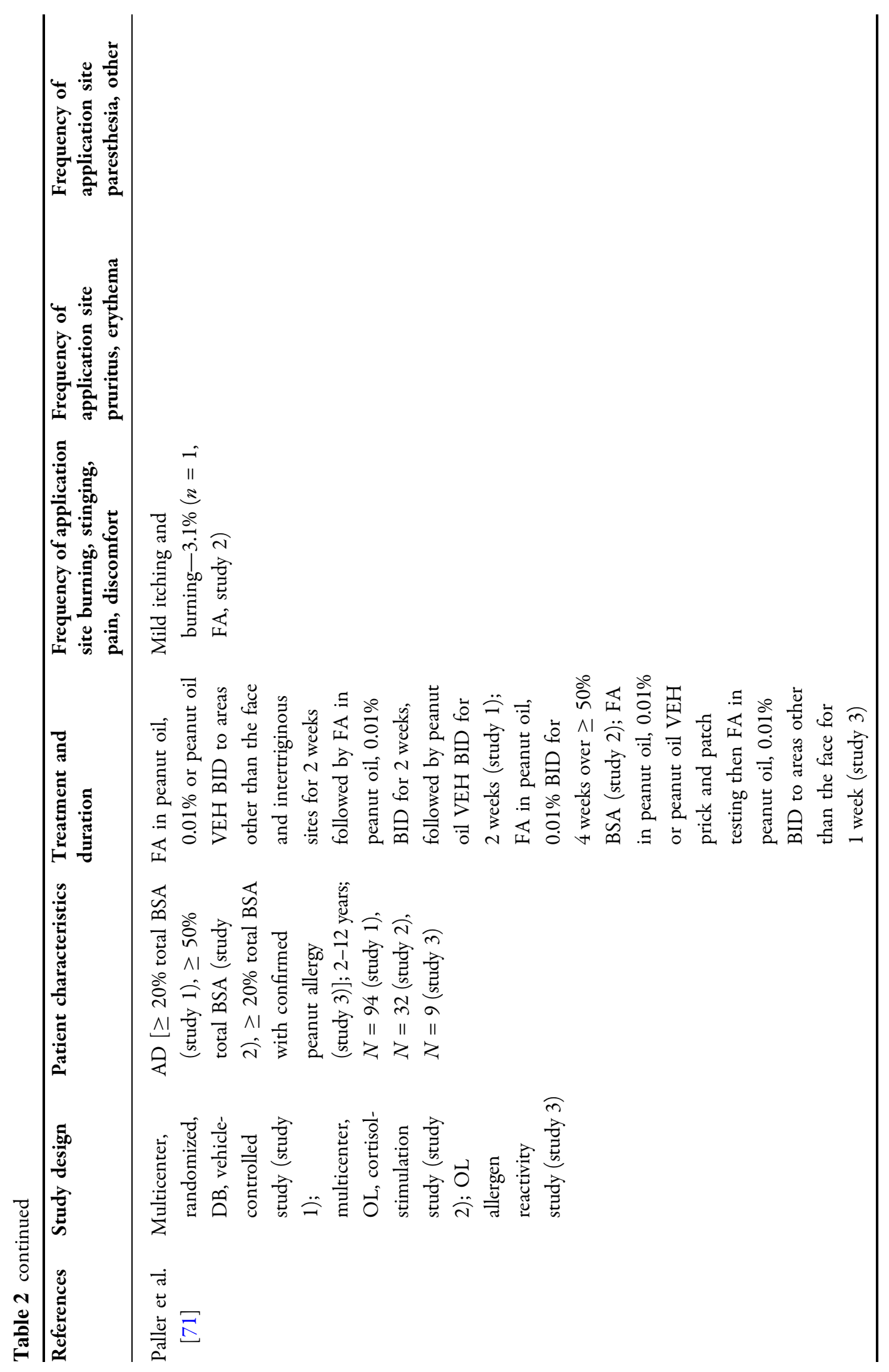




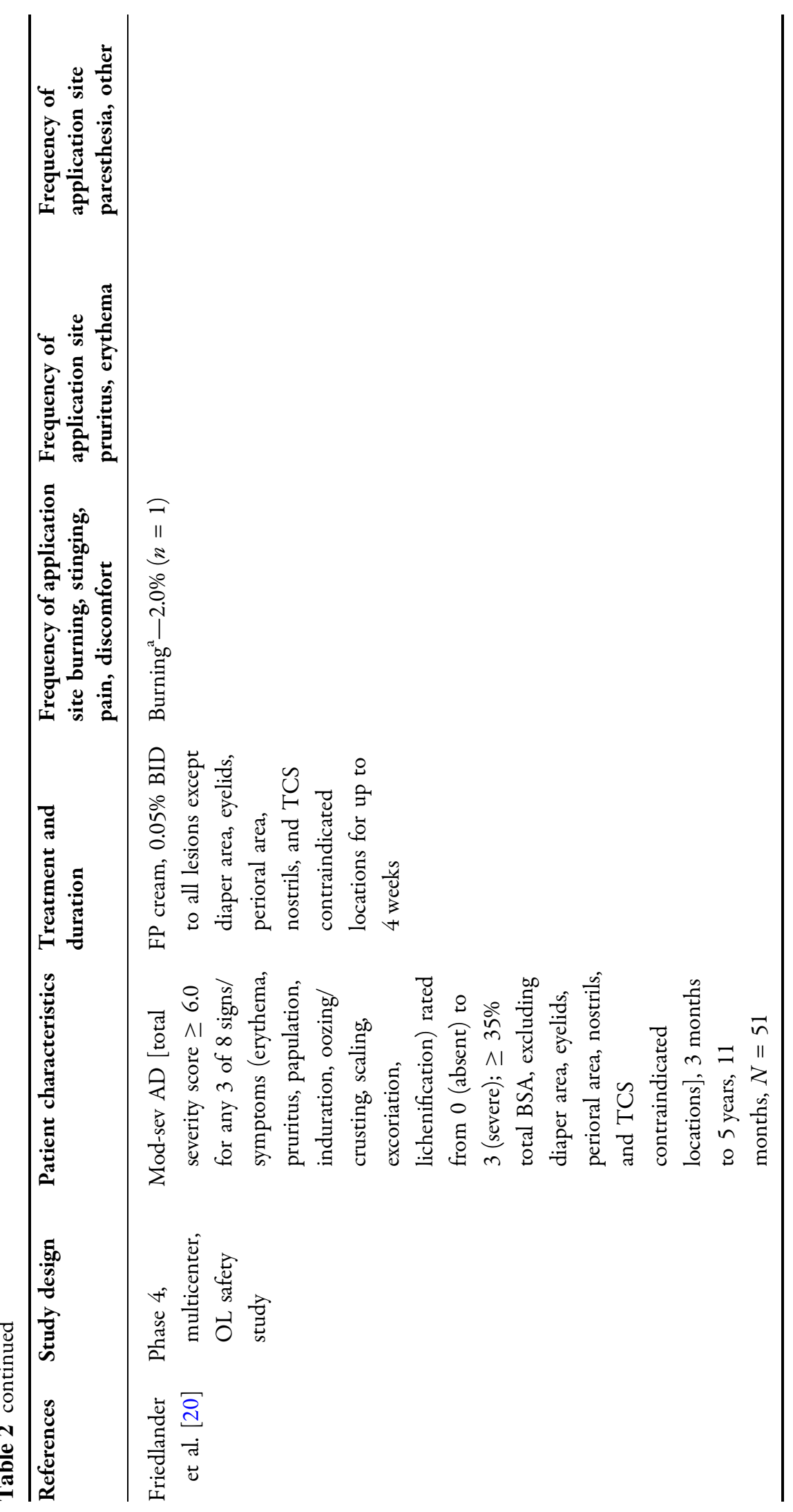




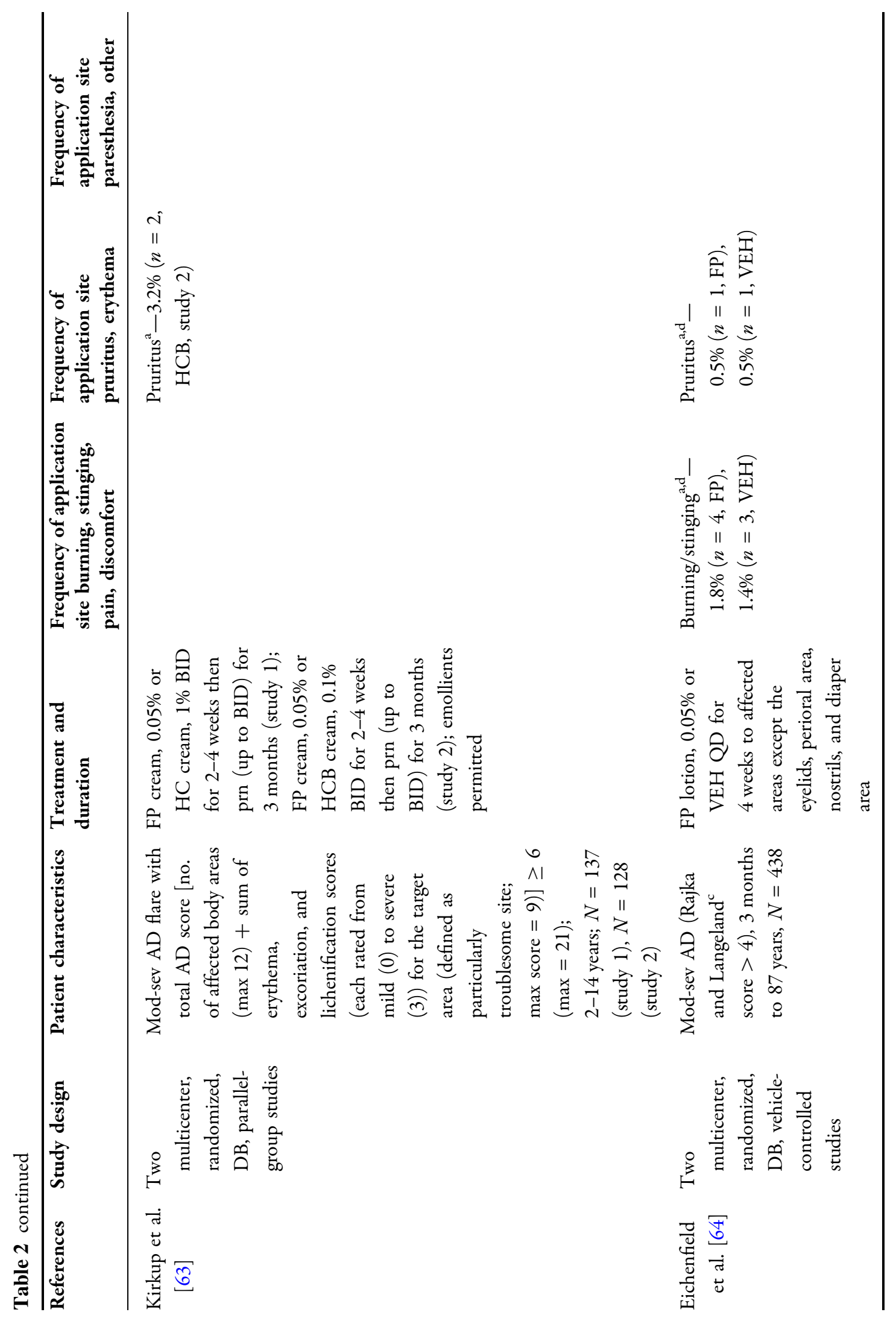




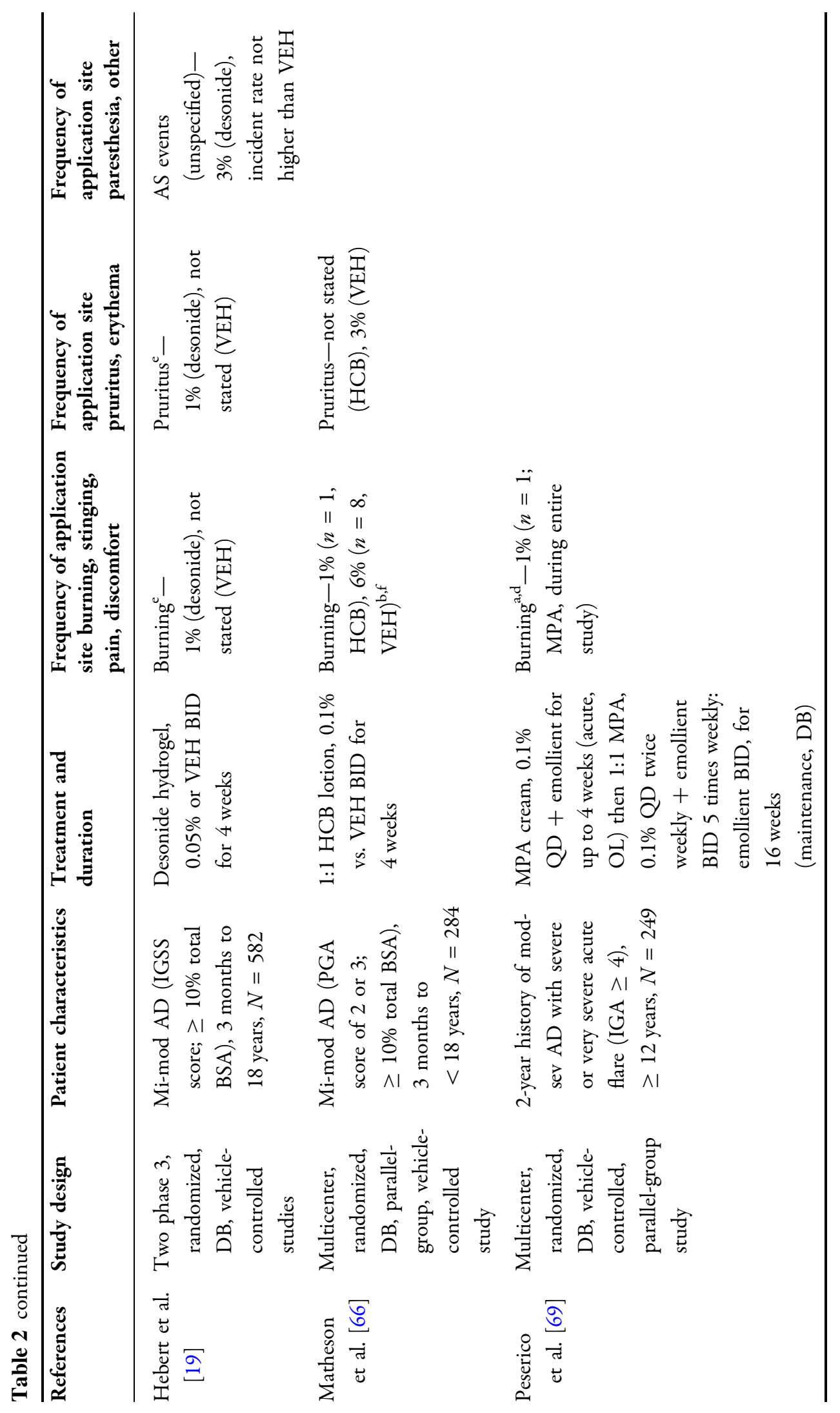




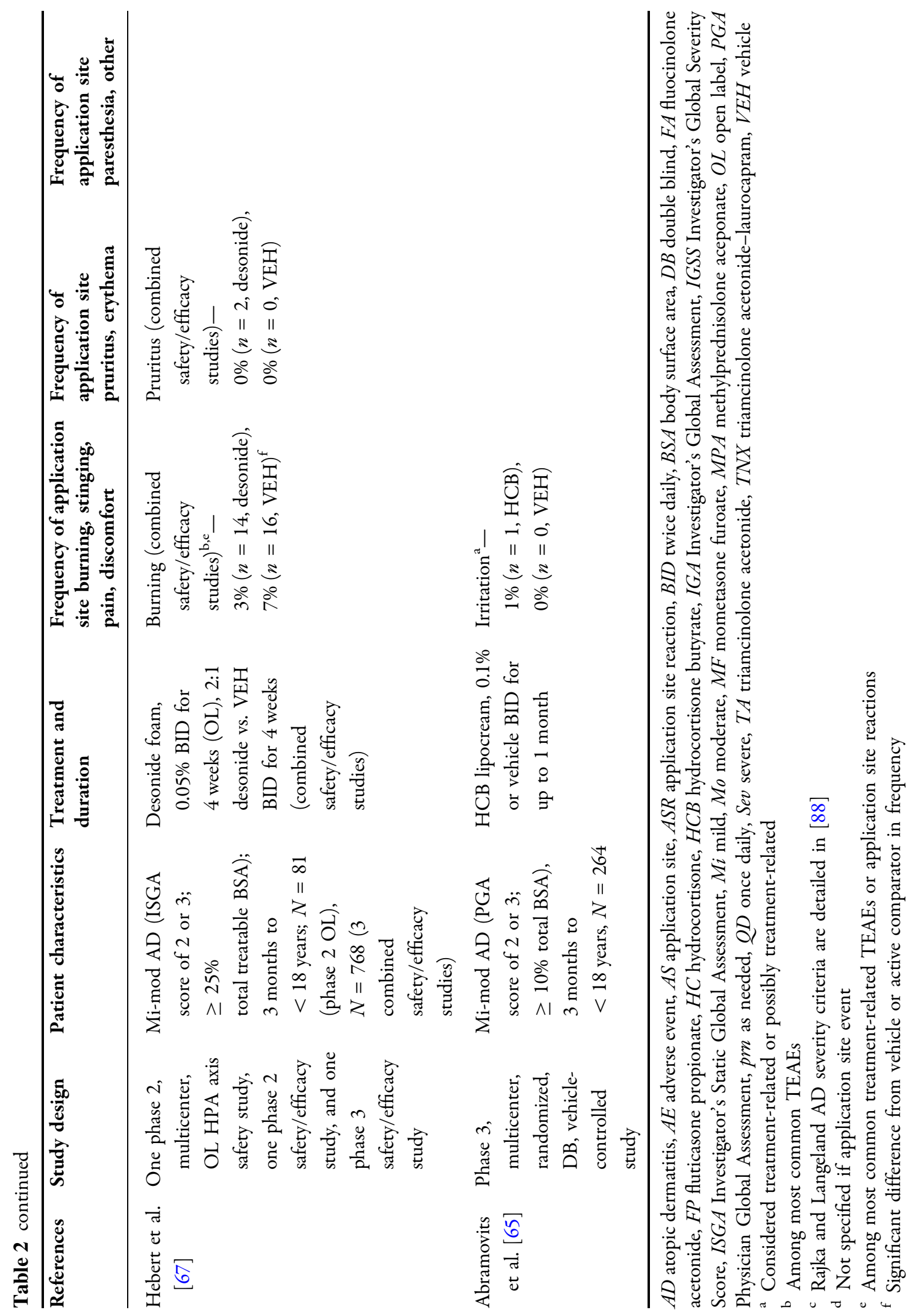


or methylprednisolone aceponate (MPA) cream, $0.1 \%$ [69] was associated with relatively low rates of tolerability issues. AS warmth was reported in $1.5 \%$ of adult patients treated with MF cream, and MPA-related burning occurred in less than $1 \%$ of adolescent and adult patients with an acute flare of moderate to severe AD.

The remaining TCS trials evaluated triamcinolone acetonide (TA) [70], triamcinolone acetonide-laurocapram (TNX) [70], and fluocinolone acetonide (FA), $0.01 \%$ in peanut oil [71]. A study of 2 weeks of treatment with TA, TNX, or vehicle in adults with $\mathrm{AD}$ reported rates of AS burning, pruritus, or disease exacerbation of $4 \%$ (TA), $6 \%$ (TNX), and 12\% (vehicle) [70]. These were the highest rates of AS tolerability issues reported among TCS studies but may reflect the fact that all AS reactions were reported together. Mild AS itching and burning $(3.1 \%)$ were reported during a 4-week openlabel trial of FA in children with AD (study 2 of three trials reported in [71]).

\section{TOLERABILITY FINDINGS FROM HEAD-TO-HEAD COMPARISONS OF TCIs and TCSs}

Nine studies directly compared TCIs to TCSs, of which four reported significantly greater rates of AS burning, pruritus, or tingling in TCI treatment groups (Table 3) [72-80]. Luger et al. [72] compared up to 1 year of combination TCS therapy with TA cream, $0.1 \%$ and hydrocortisone acetate (HA) cream, 1\% to TCI therapy with pimecrolimus cream, $1 \%$. AS tolerability issues were numerically more frequent with pimecrolimus (burning, 25.9\%; pruritus, 5.5\%) than TA/HA combination therapy (burning, $10.9 \%$; pruritus, $1.8 \%$ ), and AS issues were mild to moderate, resolved within 7 days, and occurred early in treatment.

Three studies compared tacrolimus ointment $(0.1 \%$ and/or $0.03 \%)$ to HA ointment, $1 \%$ over a 3-week treatment period in children/adolescents and reported a range of tolerability issues [73-75]. For twice-daily treatment, rates of skin burning across studies for tacrolimus, $0.03 \%$, tacrolimus, $0.1 \%$ and HA ranged from $18.5 \%$ to $23.8 \%, 20.4 \%$, and $3.3 \%$ to $14.5 \%$, respectively.
A study with $3.3 \%$ rate of burning in HA patients did not indicate whether burning sensation was AS-specific. Rates of AS pruritus across studies ranged from $10.0 \%$ to $21.4 \%$ (tacrolimus, $0.03 \%$ ), $11.3 \%$ (tacrolimus, $0.1 \%$ ), and $3.3 \%$ to $15.9 \%(\mathrm{HA})$. Two of the three studies $[73,74]$ reported significantly greater rates $(p<0.05)$ of AS burning in tacrolimustreated children and adolescents with moderate to severe AD compared with the HA group. Both studies reporting significant differences indicated that tolerability issues were predominantly mild to moderate and decreased in prevalence over the 3 weeks of treatment, with highest rates observed on days 1-4.

Two studies compared tacrolimus to HCB ointment, $0.1 \%$ in adults with moderate to severe $\mathrm{AD}$, reporting more tolerability issues in TCI than TCS treatment groups. Reitamo et al. [76] compared up to 6 months of therapy with $0.1 \% \mathrm{HCB}$ and $1 \% \mathrm{HA}$ to tacrolimus (TAC), $0.1 \%$ and reported significantly greater rates of skin tingling (TCS, $0.6 \%$; TAC, $2.7 \% ; p=0.02$ ) and burning (TCS, 13.8\%; TAC, 52.4\%; $p<0.001)$ in the tacrolimus treatment group than in the TCS group. Another study by Reitamo et al. [78] compared 3 weeks of therapy with $\mathrm{HCB}, 1 \%$ to tacrolimus, $0.03 \%$ or $0.1 \%$ and reported significantly greater rates of AS burning [Table 3; HCB, $12.9 \%$; TAC $(0.03 \%), 45.1 \%$; TAC $(0.1 \%), 59.2 \% ; p<0.05$ for TAC treatments vs $\mathrm{HCB}$ ] and pruritus [Table 3; HCB, 9.7\%; TAC $(0.03 \%), 20.2 \%$; TAC $(0.1 \%), 15.2 \% ; p<0.05$ for TAC treatments vs HCB] in tacrolimus-treated patients. Tolerability issues decreased in prevalence over time in both studies. The highest rates of AS burning and pruritus events were observed on days 1-4 in the 3-week study, and the highest AS burning rates were observed during the first week of the 6-month study.

Two studies compared short-term (3-6 weeks) treatment with fluticasone ointment, $0.005 \%$ to tacrolimus $(0.03 \%$ or $0.1 \%)$, and reported an overall pattern of more tolerability issues in tacrolimus than in fluticasone treatment groups. Doss et al. [79] reported a higher rate of AS skin burning sensation in tacrolimus-treated patients (TAC 0.03\%, 7.6\%; fluticasone, 2.5\%) that contributed to a significant difference in frequency of unspecified AS AEs (TAC 0.03\%, 
18.0\%; fluticasone, $11.3 \% ; p=0.038$ ) between the two treatment arms during the first 3 weeks of the study. Another study by Doss et al. [80] reported rates of AS burning and pruritus specific to facial and nonfacial areas (see Table 3 for full list) that were numerically higher in the tacrolimus, $0.1 \%$ group than in the fluticasone group for facial areas but not significantly different.

Bieber et al. [77] compared 3 weeks of treatment with MPA ointment, $0.1 \%$ to tacrolimus, $0.03 \%$ in children with severe or very severe acute AD flares, showing a numerically higher incidence of AEs in the tacrolimus group (4.4\%) than in the MPA group (0\%), with the tacrolimus-treated patients reporting these events as pruritus, erythema, skin burning, and hot flushes.

Taken together, studies directly comparing TCIs with TCSs suggest that AS tolerability issues are more common with TCI treatment than with TCS treatment but tend to decrease over time. This may be related to improved skin barrier function resulting in lower skin penetration with continued use [81]. However, definitive conclusions are limited by differences in study design and reporting of events. Furthermore, literature reporting comparisons of pimecrolimus to TCS therapy is very limited.

\section{TOLERABILITY OF CRISABOROLE}

In two identically designed, 4-week phase 3 trials (studies AD-301 and AD-302) of crisaborole ointment, $2 \%$ in $\mathrm{AD}$ patients at least 2 years of age with mild to moderate $\mathrm{AD}$, most treatment-related AEs involved AS pain (defined as burning or stinging), which was reported in $4.4 \%$ of crisaborole-treated patients and $1.2 \%$ of vehicle-treated patients (Table 4; pooled data, $p=0.001$ ) [21]. Most patients (76.7\%) experiencing AS pain reported the AE on the first day of treatment, and most $(77.6 \%)$ reported resolution within 1 day of onset. In a 48-week openlabel, single-arm safety extension trial (study AD-303), treatment-related AS pain was reported in $2.3 \%$ of crisaborole-treated patients ( $n=12$; onset in AD-301/AD-302, $n=6$; onset in $\mathrm{AD}-303, n=6$ ) [22]. AS pain events in crisaborole-treated patients enrolled in AD-303 had a median duration of 5 days, and 33\% resolved within 1 day of onset.

\section{POTENTIAL STRATEGIES FOR MANAGING TOLERABILITY ISSUES ASSOCIATED WITH TOPICAL TREATMENTS FOR AD}

AS tolerability issues were observed for all three drug classes in this analysis, underscoring the need for mitigation strategies in affected patients. Accordingly, American Academy of Dermatology (AAD) and American Academy of Allergy, Asthma \& Immunology (AAAAI) guidelines recommend patient counseling, whereby physicians advise patients to anticipate transient burning and stinging with TCI application [10, 11]. AAD, AAAAI, and European Academy of Dermatology and Venereology (EADV) guidelines also recommend integration of regular emollient use into $\mathrm{AD}$ treatment plans to maintain skin barrier function, alleviate symptoms of $\mathrm{AD}$, and reduce irritation [10-12]. Emollients improve signs and symptoms of $\mathrm{AD}$ while demonstrating good tolerability [82]. However, skin stinging/burning and pruritus have been reported in trials of some emollient formulations [15-18]; therefore, the optimal moisturizer should be devoid of ingredients that are irritating or sensitizing to the patient [83]. In the case of an acute $\mathrm{AD}$ flare, AAD [10] and EADV [12] guidelines suggest preceding TCI treatment with TCS treatment to restore skin barrier function so that large molecules (larger than 500 Daltons such as pimecrolimus and tacrolimus) cannot easily penetrate the skin (i.e., the 500-Dalton rule) [84], thereby minimizing TCI-associated AS tolerability issues [10, 12].

Additional published recommendations suggest administering oral aspirin [85]. A small retrospective study reported that $500 \mathrm{mg}$ oral aspirin taken $1 \mathrm{~h}$ before initial tacrolimus reapplication reduced to mild $(n=3)$ or prevented $(n=3)$ burning as assessed during follow-up interviews by six adult patients who had discontinued tacrolimus because of severe burning [85]. Potential mediators of the anti-burning effect of aspirin are inhibition of 


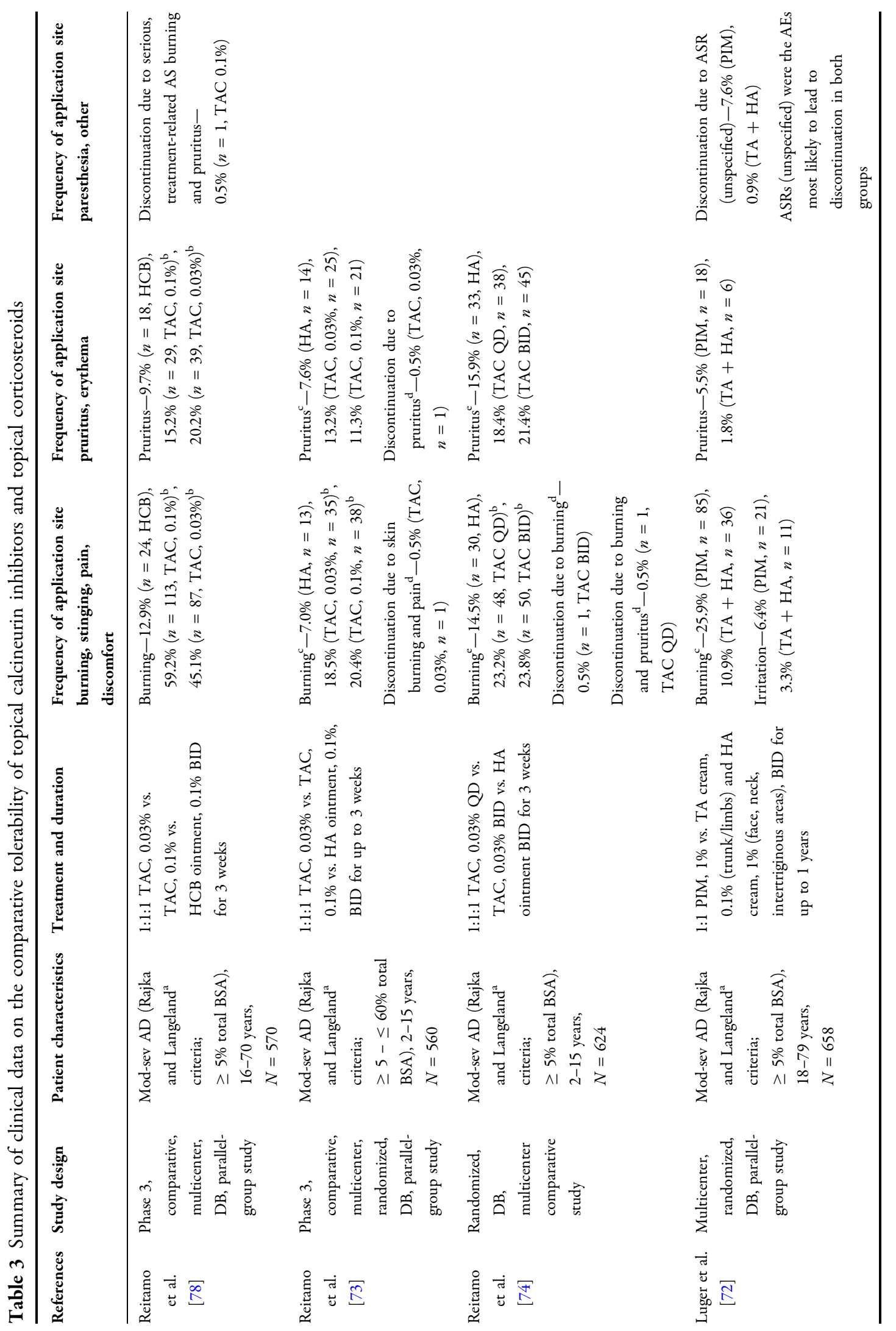




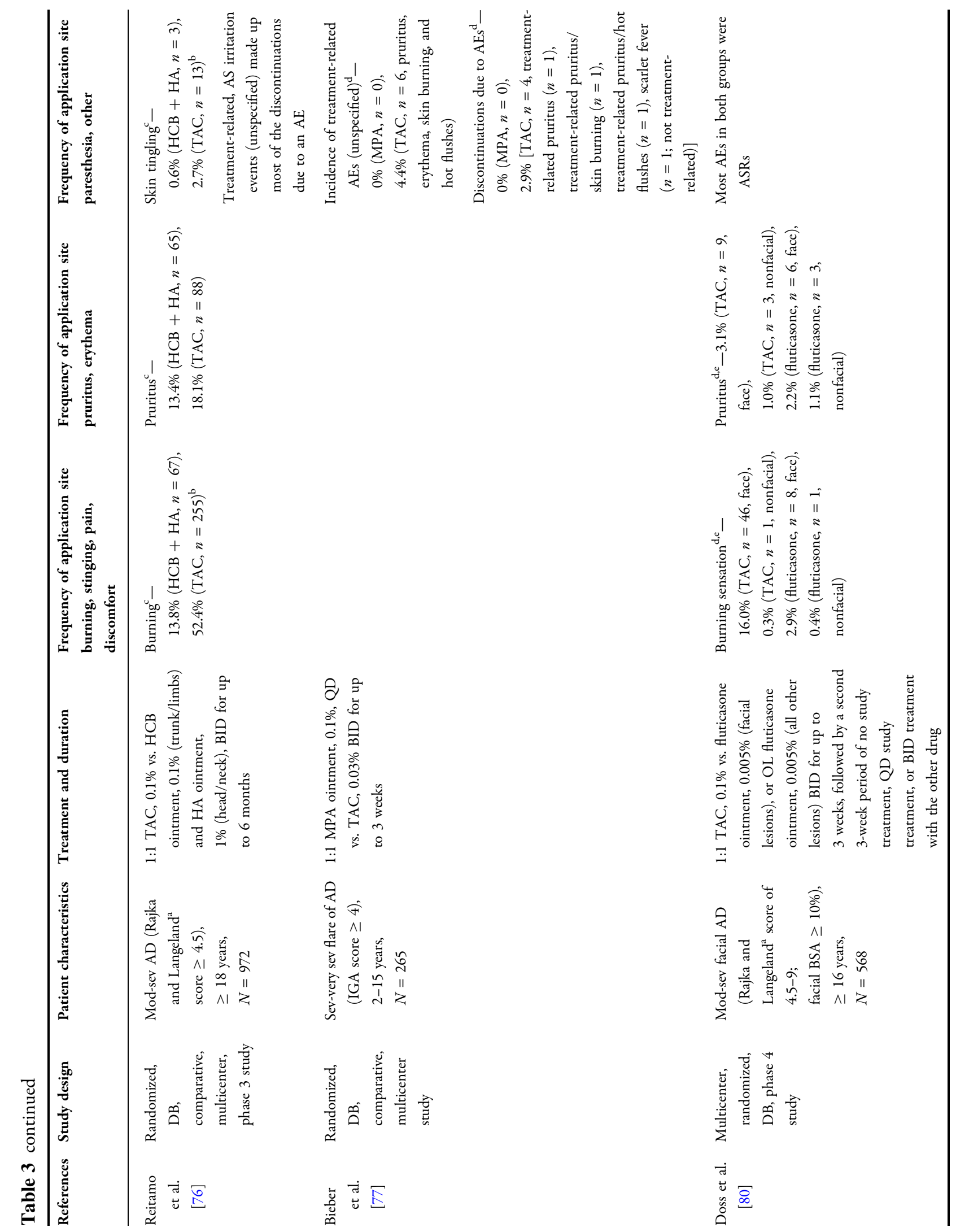




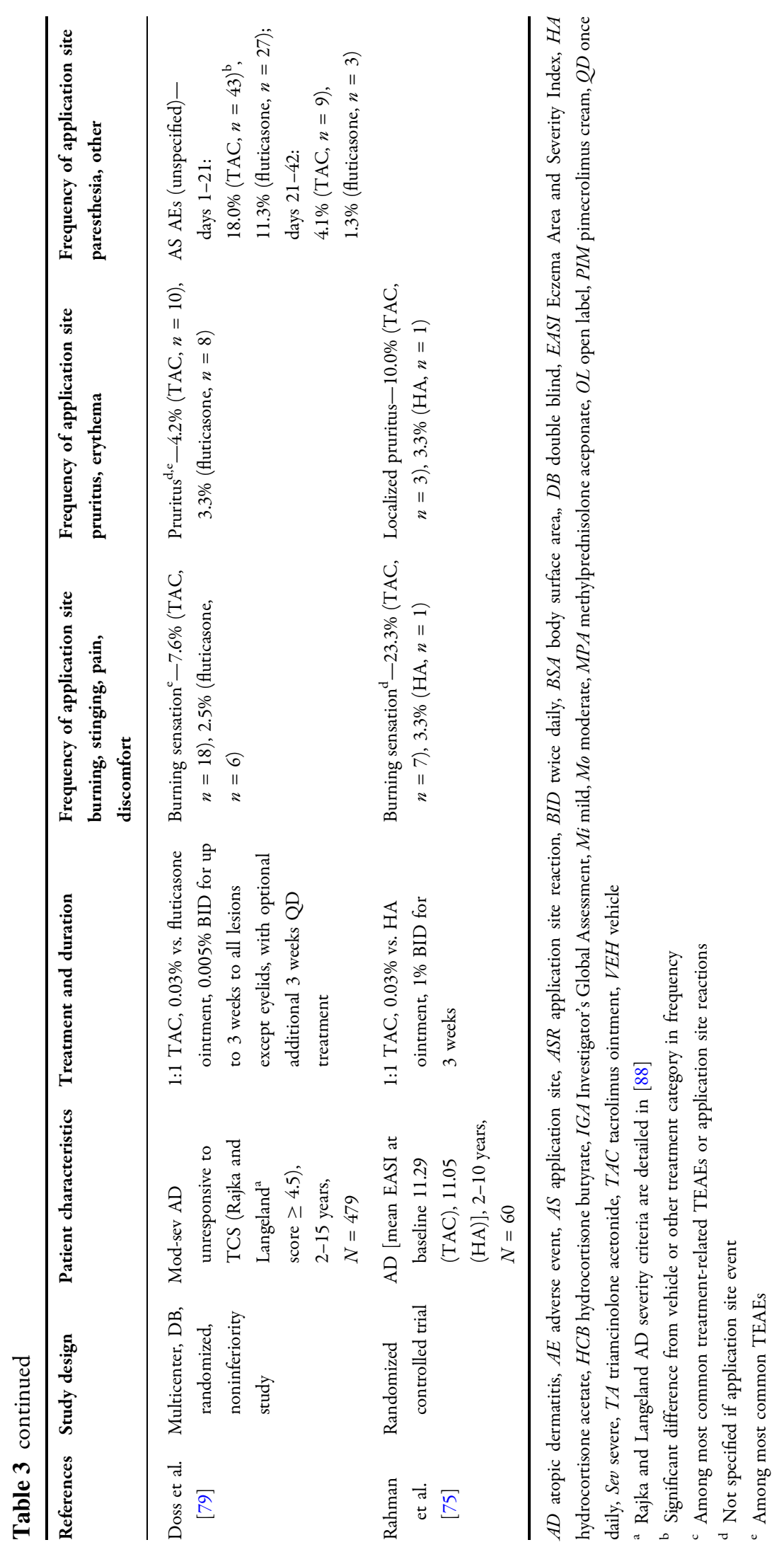




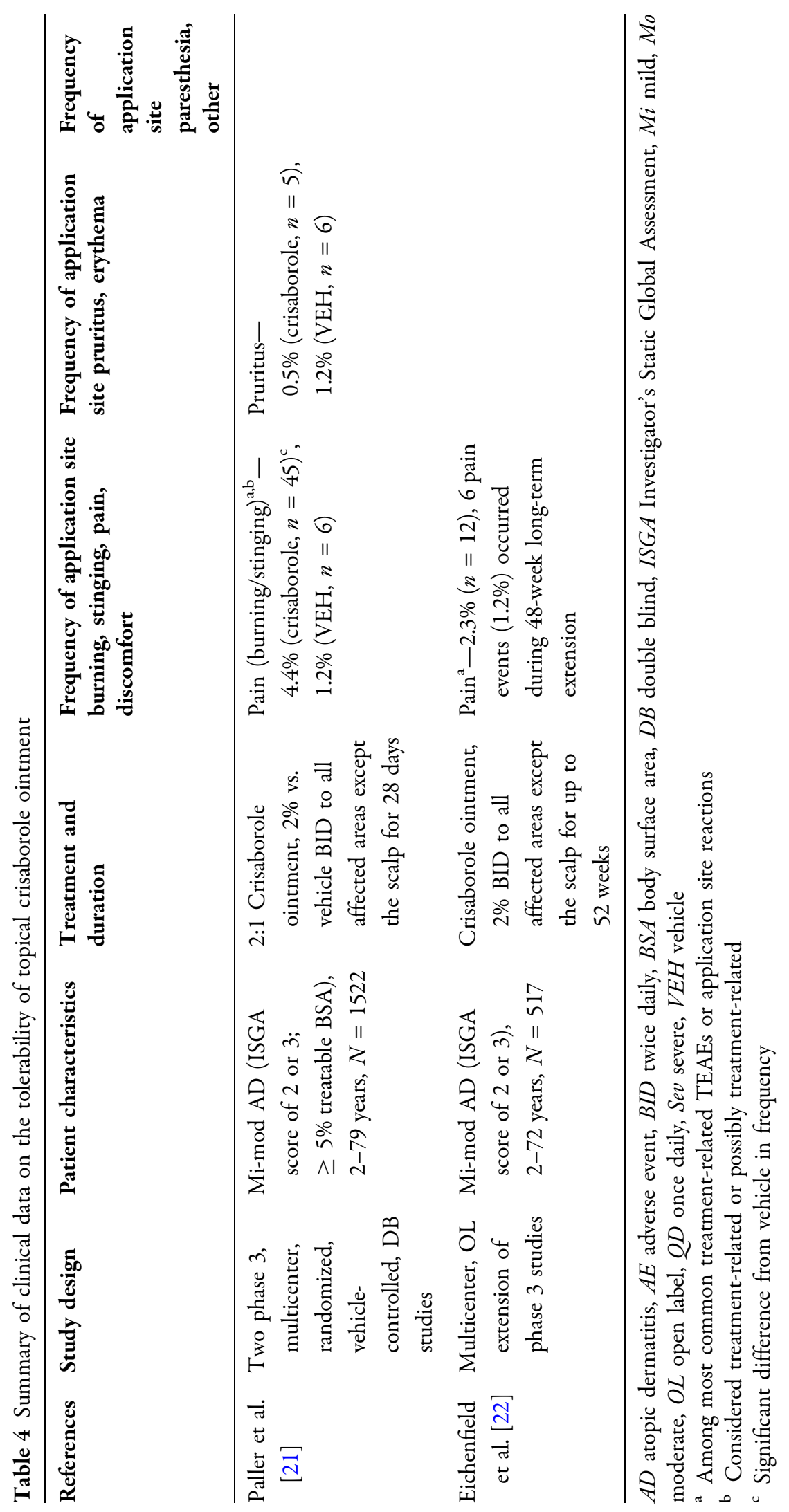


cyclooxygenase and downstream prostaglandin synthesis and inhibition of the TRPV1 heat/ pain receptor [86], which is activated following exposure to tacrolimus in an in vitro porcine model [87].

\section{CONCLUSIONS}

Baseline skin pain is common in AD patients, and application of topical therapies can result in AS tolerability issues. In this review of studies evaluating AS reactions to prescription topical therapies, AS tolerability issues, including burning, stinging, and pruritus, occurred at highest frequency in TCIs, followed by crisaborole and TCSs. Comparing these findings merits caution because of differences in study design that complicate direct comparisons of tolerability. Prevalence rates of AS tolerability issues ranged broadly for individual drug classes, and rates in head-to-head comparisons were often quite different than those in studies investigating a single drug class, a pattern that was especially evident for TCSs. Studies included in this analysis often did not provide detailed information about AS specificity, severity, duration, and direct relation to treatment of tolerability issues. There are no completed head-to-head studies comparing crisaborole with TCIs or TCSs; therefore, informed comparisons of AS tolerability cannot be made. Useful strategies for mitigating AS tolerability issues include patient counseling to anticipate AS tolerability issues and regular use of emollients. Further research is needed to understand mechanisms of AS reactions and patient baseline pain/sensitivity. This mechanistic research may inform formulations with improved tolerability or more efficient, personalized selection of topical products best suited to a patient's skin sensitivity and $\mathrm{AD}$ severity.

\section{ACKNOWLEDGEMENTS}

Funding. This research was funded by Pfizer Inc., New York, NY. Article processing charges were funded by Pfizer Inc.
Medical Writing, Editorial, or Other Assistance. Medical writing and editorial assistance under the guidance of the authors was provided by Madeline L. Pfau, Ph.D., and Corey Mandel, Ph.D. (ApotheCom, New York, NY, and San Francisco, CA, respectively) and funded by Pfizer Inc. in accordance with Good Publication Practice (GPP3) guidelines (Ann Intern Med. 2015;163:461-464).

Authorship. All named authors meet the International Committee of Medical Journal Editors (ICMJE) criteria for authorship for this manuscript, take responsibility for the integrity of the work as a whole, and have given final approval to the version to be published.

Disclosures. Zoe D. Draelos has nothing to disclose. Steven R. Feldman has received speaking, consulting, and/or research support from Galderma, GSK/Stiefel, Almirall, Leo Pharma, Boehringer Ingelheim, Mylan, Celgene, Pfizer, Valeant, AbbVie, Samsung, Janssen, Lilly, Menlo, Merck, Novartis, Regeneron, Sanofi, Novan, Qurient, National Biologic Corporation, and Sun Pharma. Brian Berman has received grants from Anacor Pharmaceuticals, a wholly owned subsidiary of Pfizer, and Pfizer. Brian Berman has served as a consultant and investigator for Anacor Pharmaceuticals, a wholly owned subsidiary of Pfizer, and as a consultant for Pfizer. Melissa Olivadoti is an employee and stockholder of Pfizer Inc. Michael A. Zielinski is an employee and stockholder of Pfizer Inc. William C. Ports is an employee and stockholder of Pfizer Inc. Sheryl Baldwin is an employee and stockholder of Pfizer Inc. Anna M. Tallman was an employee and stockholder of Pfizer Inc. at the time of manuscript conception and initiation. Anna M. Tallman is now an employee of Dermavant Sciences, Inc., New York, NY. Debra Sierka was an employee and stockholder of Pfizer Inc. at the time of manuscript conception and initiation. Debra Sierka is now an employee of Sanofi, Cambridge, MA.

Compliance with Ethics Guidelines. This article is based on previously conducted studies and does not contain any studies with human 
participants or animals performed by any of the authors.

Data Availability. Data sharing is not applicable to this article as no datasets were generated or analyzed during the current study.

Open Access. This article is distributed under the terms of the Creative Commons Attribution-NonCommercial 4.0 International License (http://creativecommons.org/licenses/ by-nc/4.0/), which permits any noncommercial use, distribution, and reproduction in any medium, provided you give appropriate credit to the original author(s) and the source, provide a link to the Creative Commons license, and indicate if changes were made.

\section{REFERENCES}

1. Bieber T. Atopic dermatitis. $\mathrm{N}$ Engl J Med. 2008;358(14):1483-94. https://doi.org/10.1056/ NEJMra074081.

2. Bieber T. Atopic dermatitis. Ann Dermatol. 2010;22(2):125-37. https://doi.org/10.5021/ad. 2010.22.2.125.

3. Vakharia PP, Chopra R, Sacotte R, et al. Burden of skin pain in atopic dermatitis. Ann Allergy Asthma Immunol. 2017;119(6):548-52.e3. https://doi.org/ 10.1016/j.anai.2017.09.076.

4. O'Neill JL, Chan YH, Rapp SR, Yosipovitch G. Differences in itch characteristics between psoriasis and atopic dermatitis patients: results of a webbased questionnaire. Acta Derm Venereol. 2011;91(5):537-40. https://doi.org/10.2340/ $00015555-1126$.

5. Brenaut E, Garlantezec R, Talour K, Misery L. Itch characteristics in five dermatoses: non-atopic eczema, atopic dermatitis, urticaria, psoriasis and scabies. Acta Derm Venereol. 2013;93(5):573-4. https://doi.org/10.2340/00015555-1599.

6. Yatagai T, Shimauchi T, Yamaguchi H, et al. Sensitive skin is highly frequent in extrinsic atopic dermatitis and correlates with disease severity markers but not necessarily with skin barrier impairment. J Dermatol Sci. 2018;89(1):33-9. https://doi.org/10. 1016/j.jdermsci.2017.10.011.

7. Andersen $\mathrm{HH}$, Elberling J, Solvsten H, Yosipovitch G, Arendt-Nielsen L. Nonhistaminergic and mechanical itch sensitization in atopic dermatitis. Pain. 2017;158(9):1780-91. https://doi.org/10. 1097/j.pain.0000000000000980.

8. Misery L, Loser K, Stander S. Sensitive skin. J Eur Acad Dermatol Venereol. 2016;30(Suppl 1):2-8. https://doi.org/10.1111/jdv.13532.

9. Tsutsumi M, Kitahata H, Fukuda M, et al. Numerical and comparative three-dimensional structural analysis of peripheral nerve fibres in epidermis of patients with atopic dermatitis. Br J Dermatol. 2016;174(1):191-4. https://doi.org/10.1111/bjd. 13974.

10. Eichenfield LF, Tom WL, Berger TG, et al. Guidelines of care for the management of atopic dermatitis: section 2. Management and treatment of atopic dermatitis with topical therapies. J Am Acad Dermatol. 2014;71(1):116-32. https://doi.org/10.1016/ j.jaad.2014.03.023.

11. Schneider L, Tilles S, Lio P, et al. Atopic dermatitis: a practice parameter update 2012. J Allergy Clin Immunol. 2013;131(2):295-9.e27. https://doi.org/ 10.1016/j.jaci.2012.12.672.

12. Wollenberg A, Barbarot S, Bieber T, et al. Consensus-based European guidelines for treatment of atopic eczema (atopic dermatitis) in adults and children: part I. J Eur Acad Dermatol Venereol. 2018;32(5):657-82. https://doi.org/10.1111/jdv. 14891.

13. Anacor Pharmaceuticals. EUCRISA (crisaborole) ointment, 2\%, for topical use. Palo Alto: Anacor Pharmaceuticals; 2016.

14. Boguniewicz M, Fonacier L, Guttman-Yassky E, Ong PY, Silverberg J, Farrar JR. Atopic dermatitis yardstick: practical recommendations for an evolving therapeutic landscape. Ann Allergy Asthma Immunol. 2018;120(1):10-22.e2. https://doi.org/10.1016/ j.anai.2017.10.039.

15. Akerstrom U, Reitamo S, Langeland T, et al. Comparison of moisturizing creams for the prevention of atopic dermatitis relapse: a randomized doubleblind controlled multicentre clinical trial. Acta Derm Venereol. 2015;95(5):587-92. https://doi.org/ 10.2340/00015555-2051.

16. Angelova-Fischer I, Neufang G, Jung K, Fischer TW, Zillikens D. A randomized, investigator-blinded efficacy assessment study of stand-alone emollient use in mild to moderately severe atopic dermatitis flares. J Eur Acad Dermatol Venereol. 2014;28(Suppl 3):9-15. https://doi.org/10.1111/jdv.12479.

17. Gayraud F, Sayag M, Jourdan E. Efficacy and tolerance assessment of a new type of dermocosmetic in infants and children with moderate atopic 
dermatitis. J Cosmet Dermatol. 2015;14(2):107-12. https://doi.org/10.1111/jocd.12145.

18. Loden M, Andersson AC, Anderson C, et al. A double-blind study comparing the effect of glycerin and urea on dry, eczematous skin in atopic patients. Acta Derm Venereol. 2002;82(1):45-7.

19. Hebert AA, Cook-Bolden FE, Basu S, Calvarese B, Trancik RJ. Safety and efficacy of desonide hydrogel $0.05 \%$ in pediatric subjects with atopic dermatitis. J Drugs Dermatol. 2007;6(2):175-81.

20. Friedlander SF, Hebert AA, Allen DB. Safety of fluticasone propionate cream $0.05 \%$ for the treatment of severe and extensive atopic dermatitis in children as young as 3 months. J Am Acad Dermatol. 2002;46(3):387-93.

21. Paller AS, Tom WL, Lebwohl MG, et al. Efficacy and safety of crisaborole ointment, a novel, nonsteroidal phosphodiesterase 4 (PDE4) inhibitor for the topical treatment of atopic dermatitis (AD) in children and adults. J Am Acad Dermatol. 2016;75(3):494-503.e6. https://doi.org/10.1016/j. jaad.2016.05.046.

22. Eichenfield LF, Call RS, Forsha DW, et al. Long-term safety of crisaborole ointment $2 \%$ in children and adults with mild to moderate atopic dermatitis. J Am Acad Dermatol. 2017;77(4):641-9.e5. https:// doi.org/10.1016/j.jaad.2017.06.010.

23. Meurer M, Eichenfield LF, Ho V, Potter PC, Werfel $\mathrm{T}$, Hultsch T. Addition of pimecrolimus cream 1\% to a topical corticosteroid treatment regimen in paediatric patients with severe atopic dermatitis: a randomized, double-blind trial. J Dermatol Treat. 2010;21(3):157-66. https://doi.org/10.3109/ 09546630903410158 .

24. Eichenfield LF, Lucky AW, Boguniewicz M, et al. Safety and efficacy of pimecrolimus (ASM 981) cream $1 \%$ in the treatment of mild and moderate atopic dermatitis in children and adolescents. J Am Acad Dermatol. 2002;46(4):495-504.

25. Kaufmann R, Bieber T, Helgesen AL, et al. Onset of pruritus relief with pimecrolimus cream $1 \%$ in adult patients with atopic dermatitis: a randomized trial. Allergy. 2006;61(3):375-81. https://doi.org/10. 1111/j.1398-9995.2005.00977.x.

26. Murrell DF, Calvieri S, Ortonne JP, et al. A randomized controlled trial of pimecrolimus cream $1 \%$ in adolescents and adults with head and neck atopic dermatitis and intolerant of, or dependent on, topical corticosteroids. $\mathrm{Br} \mathrm{J}$ Dermatol. 2007;157(5):954-9. https://doi.org/10.1111/j.13652133.2007.08192.x.
27. Hoeger PH, Lee KH, Jautova J, et al. The treatment of facial atopic dermatitis in children who are intolerant of, or dependent on, topical corticosteroids: a randomized, controlled clinical trial. $\mathrm{Br} \mathrm{J}$ Dermatol. 2009;160(2):415-22. https://doi.org/10. 1111/j.1365-2133.2008.08928.x.

28. Eichenfield LF, Lucky AW, Langley RG, et al. Use of pimecrolimus cream 1\% (Elidel) in the treatment of atopic dermatitis in infants and children: the effects of ethnic origin and baseline disease severity on treatment outcome. Int J Dermatol. 2005;44(1): 70-5. https://doi.org/10.1111/j.1365-4632.2004. 02234.x.

29. Zuberbier T, Heinzerling L, Bieber T, Schauer U, Klebs S, Brautigam M. Steroid-sparing effect of pimecrolimus cream $1 \%$ in children with severe atopic dermatitis. Dermatology. 2007;215(4): 325-30. https://doi.org/10.1159/000107627.

30. Zuberbier T, Brautigam M. Long-term management of facial atopic eczema with pimecrolimus cream $1 \%$ in paediatric patients with mild to moderate disease. J Eur Acad Dermatol Venereol. 2008;22(6):718-21. https://doi.org/10.1111/j.14683083.2008.02586.x.

31. Sigurgeirsson B, Ho V, Ferrandiz C, Andriano K, Grinienko A, Jimenez P. Effectiveness and safety of a prevention-of-flare-progression strategy with pimecrolimus cream $1 \%$ in the management of paediatric atopic dermatitis. J Eur Acad Dermatol Venereol. 2008;22(11):1290-301. https://doi.org/ 10.1111/j.1468-3083.2008.02785.x.

32. Wahn U, Bos JD, Goodfield M, et al. Efficacy and safety of pimecrolimus cream in the long-term management of atopic dermatitis in children. Pediatrics. 2002;110(1 Pt 1):e2.

33. Meurer M, Fartasch M, Albrecht G, et al. Long-term efficacy and safety of pimecrolimus cream $1 \%$ in adults with moderate atopic dermatitis. Dermatology (Basel, Switzerland). 2004;208(4):365-72. https://doi.org/10.1159/000078462.

34. Meurer M, Folster-Holst R, Wozel G, Weidinger G, Junger $M$, Brautigam $M$. Pimecrolimus cream in the long-term management of atopic dermatitis in adults: a six-month study. Dermatology. 2002;205(3):271-7. https://doi.org/10.1159/000065863.

35. Lubbe J, Friedlander SF, Cribier B, et al. Safety, efficacy, and dosage of $1 \%$ pimecrolimus cream for the treatment of atopic dermatitis in daily practice. Am J Clin Dermatol. 2006;7(2):121-31. https://doi. org/10.2165/00128071-200607020-00005.

36. Simon D, Lubbe J, Wuthrich B, et al. Benefits from the use of a pimecrolimus-based treatment in the management of atopic dermatitis in clinical 
practice. Analysis of a Swiss cohort. Dermatology. 2006;213(4):313-8. https://doi.org/10.1159/ 000096195 .

37. Ring J, Abraham A, de Cuyper C, Kim K, Langeland $\mathrm{T}$, Parra V, et al. Control of atopic eczema with pimecrolimus cream $1 \%$ under daily practice conditions: results of a $>2000$ patient study. J Eur Acad Dermatol Venereol JEADV. 2008;22(2):195-203. https://doi.org/10.1111/j.1468-3083.2007.02368.x.

38. De Backer M, Morren MA, Boonen H, et al. Belgian observational drug utilization study of pimecrolimus cream $1 \%$ in routine daily practice in atopic dermatitis. Dermatology (Basel, Switzerland). 2008;217(2):156-63. https://doi.org/10.1159/ 000136654 .

39. Langley RG, Eichenfield LF, Lucky AW, Boguniewicz M, Barbier N, Cherill R. Sustained efficacy and safety of pimecrolimus cream $1 \%$ when used long-term (up to 26 weeks) to treat children with atopic dermatitis. Pediatr Dermatol. 2008;25(3): 301-7. https://doi.org/10.1111/j.1525-1470.2008. 00671.x.

40. Ruer-Mulard M, Aberer W, Gunstone A, et al. Twicedaily versus once-daily applications of pimecrolimus cream $1 \%$ for the prevention of disease relapse in pediatric patients with atopic dermatitis. Pediatr Dermatol. 2009;26(5):551-8. https://doi. org/10.1111/j.1525-1470.2009.00981.x.

41. Ho VC, Gupta A, Kaufmann R, et al. Safety and efficacy of nonsteroid pimecrolimus cream $1 \%$ in the treatment of atopic dermatitis in infants. J Pediatr. 2003;142(2):155-62. https://doi.org/10.1067/ mpd.2003.65.

42. Kang S, Paller A, Soter N, Satoi Y, Rico MJ, Hanifin JM. Safe treatment of head/neck AD with tacrolimus ointment. J Dermatol Treat. 2003;14(2):86-94.

43. Lan CC, Huang CC, Chen YT, Wang LF, Lin CT, Chen GS. Tacrolimus ointment for the treatment of atopic dermatitis: report of first clinical experience in Taiwan. Kaohsiung J Med Sci. 2003;19(6): 296-304. https://doi.org/10.1016/S1607-551X(09) 70476-0.

44. Schachner LA, Lamerson C, Sheehan MP, et al. Tacrolimus ointment $0.03 \%$ is safe and effective for the treatment of mild to moderate atopic dermatitis in pediatric patients: results from a randomized, double-blind, vehicle-controlled study. Pediatrics. 2005;116(3):e334-42. https://doi.org/10.1542/peds. 2004-2638.

45. Singalavanija S, Noppakun N, Limpongsanuruk W, et al. Efficacy and safety of tacrolimus ointment in pediatric patients with moderate to severe atopic dermatitis. J Med Assoc Thai. 2006;89(11):1915-22.
46. Won CH, Seo PG, Park YM, et al. A multicenter trial of the efficacy and safety of $0.03 \%$ tacrolimus ointment for atopic dermatitis in Korea. J Dermatol Treat. 2004;15(1):30-4. https://doi.org/10.1080/ 09541440042000269 .

47. Tan J, Langley R. Safety and efficacy of tacrolimus ointment $0.1 \%$ (protopic) in atopic dermatitis: a Canadian open-label multicenter study. J Cutan Med Surg. 2004;8(4):213-9. https://doi.org/10. $1177 / 120347540400800402$.

48. Reitamo S, Wollenberg A, Schopf E, et al. Safety and efficacy of 1 year of tacrolimus ointment monotherapy in adults with atopic dermatitis. The European Tacrolimus Ointment Study Group. Arch Dermatol. 2000;136(8):999-1006.

49. Reitamo S, Ortonne JP, Sand C, et al. Long-term treatment with $0.1 \%$ tacrolimus ointment in adults with atopic dermatitis: results of a two-year, multicentre, non-comparative study. Acta Derm Venereol. 2007;87(5):406-12. https://doi.org/10. 2340/00015555-0282.

50. Remitz A, Harper J, Rustin M, et al. Long-term safety and efficacy of tacrolimus ointment for the treatment of atopic dermatitis in children. Acta Derm Venereol. 2007;87(1):54-61. https://doi.org/10. 2340/00015555-0167.

51. Reitamo S, Rustin M, Harper J, et al. A 4-year followup study of atopic dermatitis therapy with $0.1 \%$ tacrolimus ointment in children and adult patients. Br J Dermatol. 2008;159(4):942-51. https://doi.org/ 10.1111/j.1365-2133.2008.08747.x.

52. Wollenberg A, Reitamo S, Atzori F, et al. Proactive treatment of atopic dermatitis in adults with $0.1 \%$ tacrolimus ointment. Allergy. 2008;63(6):742-50. https://doi.org/10.1111/j.1398-9995.2008.01683.x.

53. Thaci D, Reitamo S, Gonzalez Ensenat MA, et al. Proactive disease management with $0.03 \%$ tacrolimus ointment for children with atopic dermatitis: results of a randomized, multicentre, comparative study. Br J Dermatol. 2008;159(6):1348-56. https:// doi.org/10.1111/j.1365-2133.2008.08813.x.

54. Reitamo S, Allsopp R. Treatment with twice-weekly tacrolimus ointment in patients with moderate to severe atopic dermatitis: results from two randomized, multicentre, comparative studies. J Dermatol Treat. 2010;21(1):34-44. https://doi.org/10.3109/ 09546630903401488 .

55. Breneman D, Fleischer AB Jr, Abramovits W, et al. Intermittent therapy for flare prevention and longterm disease control in stabilized atopic dermatitis: a randomized comparison of 3-times-weekly applications of tacrolimus ointment versus vehicle. J Am 
Acad Dermatol. 2008;58(6):990-9. https://doi.org/ 10.1016/j.jaad.2008.02.008.

56. Paller AS, Eichenfield LF, Kirsner RS, Shull T, Jaracz E, Simpson EL. Three times weekly tacrolimus ointment reduces relapse in stabilized atopic dermatitis: a new paradigm for use. Pediatrics. 2008;122(6):e1210-8. https://doi.org/10.1542/peds. 2008-1343.

57. Kempers S, Boguniewicz M, Carter E, et al. A randomized investigator-blinded study comparing pimecrolimus cream $1 \%$ with tacrolimus ointment $0.03 \%$ in the treatment of pediatric patients with moderate atopic dermatitis. J Am Acad Dermatol. 2004;51(4):515-25. https://doi.org/10.1016/j.jaad. 2004.01.051.

58. Paller AS, Lebwohl M, Fleischer AB Jr, et al. Tacrolimus ointment is more effective than pimecrolimus cream with a similar safety profile in the treatment of atopic dermatitis: results from 3 randomized, comparative studies. J Am Acad Dermatol. 2005;52(5):810-22. https://doi.org/10.1016/j.jaad. 2004.12.038.

59. Fleischer AB Jr, Abramovits W, Breneman D, Jaracz E. Tacrolimus ointment is more effective than pimecrolimus cream in adult patients with moderate to very severe atopic dermatitis. J Dermatol Treat. 2007;18(3):151-7. https://doi.org/10.1080/ 09546630701287332 .

60. Abramovits W, Fleischer AB Jr, Jaracz E, Breneman D. Adult patients with moderate atopic dermatitis: tacrolimus ointment versus pimecrolimus cream. J Drugs Dermatol. 2008;7(12):1153-8.

61. Kirsner RS, Heffernan MP, Antaya R. Safety and efficacy of tacrolimus ointment versus pimecrolimus cream in the treatment of patients with atopic dermatitis previously treated with corticosteroids. Acta Derm Venereol. 2010;90(1):58-64. https://doi.org/10.2340/00015555-0748.

62. Meingassner JG, Aschauer H, Stuetz A, Billich A. Pimecrolimus permeates less than tacrolimus through normal, inflamed, or corticosteroid-pretreated skin. Exp Dermatol. 2005;14(10):752-7. https://doi.org/10.1111/j.1600-0625.2005.00354.x.

63. Kirkup ME, Birchall NM, Weinberg EG, Helm K, Kennedy CT. Acute and maintenance treatment of atopic dermatitis in children-two comparative studies with fluticasone propionate $(0.05 \%)$ cream. J Dermatol Treat. 2003;14(3):141-8.

64. Eichenfield LF, Miller BH. Two randomized, doubleblind, placebo-controlled studies of fluticasone propionate lotion $0.05 \%$ for the treatment of atopic dermatitis in subjects from 3 months of age. J Am
Acad Dermatol. 2006;54(4):715-7. https://doi.org/ 10.1016/j.jaad.2005.10.063.

65. Abramovits W, Oquendo M. Hydrocortisone butyrate $0.1 \%$ lipocream in pediatric patients with atopic dermatitis. Skinmed. 2010;8(2):72-9.

66. Matheson R, Kempers S, Breneman D, et al. Hydrocortisone butyrate $0.1 \%$ lotion in the treatment of atopic dermatitis in pediatric subjects. J Drugs Dermatol. 2008;7(3):266-71.

67. Hebert AA. Desonide foam $0.05 \%$ : safety in children as young as 3 months. J Am Acad Dermatol. 2008;59(2):334-40. https://doi.org/10.1016/j.jaad. 2008.04.019.

68. Faergemann J, Christensen O, Sjovall P, et al. An open study of efficacy and safety of long-term treatment with mometasone furoate fatty cream in the treatment of adult patients with atopic dermatitis. J Eur Acad Dermatol Venereol. 2000;14(5):393-6.

69. Peserico A, Stadtler G, Sebastian M, Fernandez RS, Vick K, Bieber T. Reduction of relapses of atopic dermatitis with methylprednisolone aceponate cream twice weekly in addition to maintenance treatment with emollient: a multicentre, randomized, double-blind, controlled study. Br J Dermatol. 2008;158(4):801-7. https://doi.org/10.1111/j.13652133.2008.08436.x.

70. Cato A, Swinehart JM, Griffin EI, Sutton L, Kaplan AS. Azone enhances clinical effectiveness of an optimized formulation of triamcinolone acetonide in atopic dermatitis. Int $\mathrm{J}$ Dermatol. 2001;40(3):232-6.

71. Paller AS, Nimmagadda S, Schachner L, et al. Fluocinolone acetonide $0.01 \%$ in peanut oil: therapy for childhood atopic dermatitis, even in patients who are peanut sensitive. J Am Acad Dermatol. 2003;48(4):569-77. https://doi.org/10.1067/mjd. 2003.174 .

72. Luger TA, Lahfa M, Folster-Holst R, et al. Long-term safety and tolerability of pimecrolimus cream $1 \%$ and topical corticosteroids in adults with moderate to severe atopic dermatitis. J Dermatol Treat. 2004;15(3):169-78. https://doi.org/10.1080/ 09546630410033781.

73. Reitamo S, Van Leent EJ, Ho V, et al. Efficacy and safety of tacrolimus ointment compared with that of hydrocortisone acetate ointment in children with atopic dermatitis. J Allergy Clin Immunol. 2002;109(3):539-46.

74. Reitamo S, Harper J, Bos JD, et al. 0.03\% Tacrolimus ointment applied once or twice daily is more efficacious than $1 \%$ hydrocortisone acetate in children 
with moderate to severe atopic dermatitis: results of a randomized double-blind controlled trial. $\mathrm{Br} \mathrm{J}$ Dermatol. 2004;150(3):554-62. https://doi.org/10. 1046/j.1365-2133.2004.05782.x.

75. Rahman MF, Nandi AK, Kabir S, Kamal M, Basher MS, Banu LA. Topical tacrolimus versus hydrocortisone on atopic dermatitis in paediatric patients: a randomized controlled trial. Mymensingh Med J. 2015;24(3):457-63.

76. Reitamo S, Ortonne JP, Sand C, et al. A multicentre, randomized, double-blind, controlled study of long-term treatment with $0.1 \%$ tacrolimus ointment in adults with moderate to severe atopic dermatitis. Br J Dermatol. 2005;152(6):1282-9. https://doi.org/10.1111/j.1365-2133.2005.06592.x.

77. Bieber T, Vick K, Folster-Holst R, et al. Efficacy and safety of methylprednisolone aceponate ointment $0.1 \%$ compared to tacrolimus $0.03 \%$ in children and adolescents with an acute flare of severe atopic dermatitis. Allergy. 2007;62(2):184-9. https://doi. org/10.1111/j.1398-9995.2006.01269.x.

78. Reitamo S, Rustin M, Ruzicka T, et al. Efficacy and safety of tacrolimus ointment compared with that of hydrocortisone butyrate ointment in adult patients with atopic dermatitis. J Allergy Clin Immunol. 2002;109(3):547-55.

79. Doss N, Kamoun MR, Dubertret L, et al. Efficacy of tacrolimus $0.03 \%$ ointment as second-line treatment for children with moderate-to-severe atopic dermatitis: evidence from a randomized, doubleblind non-inferiority trial vs. fluticasone $0.005 \%$ ointment. Pediatr Allergy Immunol. 2010;21(2 Pt 1):321-9. https://doi.org/10.1111/j.1399-3038. 2009.00895.x.

80. Doss N, Reitamo S, Dubertret L, et al. Superiority of tacrolimus $0.1 \%$ ointment compared with fluticasone $0.005 \%$ in adults with moderate to severe atopic dermatitis of the face: results from a randomized, double-blind trial. Br J Dermatol. 2009;161(2):427-34. https://doi.org/10.1111/j. 1365-2133.2009.09143.x.
81. Siegfried EC, Jaworski JC, Hebert AA. Topical calcineurin inhibitors and lymphoma risk: evidence update with implications for daily practice. Am J Clin Dermatol. 2013;14(3):163-78. https://doi.org/ 10.1007/s40257-013-0020-1.

82. Weber TM, Herndon JH Jr, Ewer M, et al. Efficacy and tolerability of steroid-free, over-the-counter treatment formulations in infants and children with atopic dermatitis. J Dermatol Nurses Assoc. 2015;7(1):17-24. https://doi.org/10.1097/JDN. 0000000000000101.

83. van Zuuren EJ, Fedorowicz Z, Christensen R, Lavrijsen A, Arents BWM. Emollients and moisturisers for eczema. Cochrane Database Syst Rev. 2017;2:CD012119. https://doi.org/10.1002/ 14651858.cd012119.pub2.

84. Bos JD, Meinardi MM. The 500 Dalton rule for the skin penetration of chemical compounds and drugs. Exp Dermatol. 2000;9(3):165-9.

85. Mandelin J, Remitz A, Reitamo S. Effect of oral acetylsalicylic acid on burning caused by tacrolimus ointment in patients with atopic dermatitis. Arch Dermatol. 2010;146(10):1178-80. https://doi.org/ 10.1001/archdermatol.2010.275.

86. Greffrath W, Kirschstein T, Nawrath H, Treede RD. Acetylsalicylic acid reduces heat responses in rat nociceptive primary sensory neurons-evidence for a new mechanism of action. Neurosci Lett. 2002;320(1-2):61-4.

87. Pereira U, Boulais N, Lebonvallet N, Pennec JP, Dorange G, Misery L. Mechanisms of the sensory effects of tacrolimus on the skin. Br J Dermatol. 2010;163(1):70-7. https://doi.org/10.1111/j.13652133.2010.09757.x.

88. Rajka G, Langeland T. Grading of the severity of atopic dermatitis. Acta Derm Venereol Suppl. 1989;144:13-4. 